\title{
Do occupational demands explain the educational gradient in health?
}

Citation for published version (APA):

Meyer, S. C., \& Künn-Nelen, A. C. (2014). Do occupational demands explain the educational gradient in health? Maastricht University, Graduate School of Business and Economics. GSBE Research Memoranda No. 016 https://doi.org/10.26481/umagsb.2014016

Document status and date:

Published: 01/01/2014

DOI:

10.26481/umagsb.2014016

Document Version:

Publisher's PDF, also known as Version of record

\section{Please check the document version of this publication:}

- A submitted manuscript is the version of the article upon submission and before peer-review. There can be important differences between the submitted version and the official published version of record.

People interested in the research are advised to contact the author for the final version of the publication, or visit the DOI to the publisher's website.

- The final author version and the galley proof are versions of the publication after peer review.

- The final published version features the final layout of the paper including the volume, issue and page numbers.

Link to publication

\footnotetext{
General rights rights.

- You may freely distribute the URL identifying the publication in the public portal. please follow below link for the End User Agreement:

www.umlib.nl/taverne-license

Take down policy

If you believe that this document breaches copyright please contact us at:

repository@maastrichtuniversity.nl

providing details and we will investigate your claim.
}

Copyright and moral rights for the publications made accessible in the public portal are retained by the authors and/or other copyright owners and it is a condition of accessing publications that users recognise and abide by the legal requirements associated with these

- Users may download and print one copy of any publication from the public portal for the purpose of private study or research.

- You may not further distribute the material or use it for any profit-making activity or commercial gain

If the publication is distributed under the terms of Article $25 \mathrm{fa}$ of the Dutch Copyright Act, indicated by the "Taverne" license above, 


\section{Maastricht University}

Sophie-Charlotte Meyer, Annemarie Künn-Nelen

Do Occupational Demands Explain the Educational Gradient in Health?

RM/14/016

\section{GSBE}

Maastricht University School of Business and Economics

Graduate School of Business and Economics

P.O Box 616

NL-6200 MD Maastricht

The Netherlands 


\title{
Do Occupational Demands Explain the Educational Gradient in Health?
}

\author{
Sophie-Charlotte Meyer ${ }^{* 1}$, Annemarie Künn-Nelen²
}

April 2014

\begin{abstract}
The aim of this paper is to investigate to what extent occupation-specific demands explain the relationship between education and health. We concentrate on ergonomic, environmental, psychical, social and time demands. Merging the German Microcensus 2009 data with a dataset including detailed occupational demands (German Employment Survey 2006), we have a unique dataset to analyze the mediating role of occupational demands in the relationship between education and health status on the one hand and education and health behavior (BMI and smoking) on the other. We base our analyses on the entire working population and therefore also include those who no longer work, taking occupational demands related to their last job. First, we find that occupational demands are significantly related to subjective health and health behaviors. This holds even stronger for those who are no longer employed. Second, we find that whereas occupational demands do not explain educational differences in subjective health status, they do partially mediate the education gradient in the considered health behaviors. Educational differences in smoking status can partly be explained by ergonomic, environmental, psychical and social demands. The educational gradient in BMI is partly attributable to social occupational demands.
\end{abstract}

Keywords: education, occupational demands, working conditions, occupations, health, health behavior

JEL classification: I1, J2, I2

Affiliations:

1 University of Wuppertal

2 Maastricht University | ROA, IZA

\footnotetext{
* Address for Correspondence: Sophie-Charlotte Meyer, University of Wuppertal, Schumpeter School of Economics, RainerGruenter-Str. 21; 42119 Wuppertal, Germany. Email: sophie.meyer@wiwi.uni-wuppertal.de. We would like to thank Hendrik Jürges, Eric Bonsang and Bart Golsteyn for helpful comments and suggestions.
} 


\section{Introduction}

There seems to be no doubt that education is related to health. Many studies in various research disciplines have identified a strong relationship between education and a number of health outcomes and a widespread finding is that the better educated report better health and also face a lower mortality risk (for a review of the economic literature, see Cutler and Lleras-Muney 2006). In addition, some studies even found evidence that this relationship is causal, at least for men (Kemptner et al. 2011) and at older ages (Brunello et al. 2011).

Though this relationship seems to be indisputable, it is still not fully clear what the different underlying pathways are, as Grossman (2006) concludes that there is "a good deal of evidence for the proposition that the education effects are causal but it is less conclusive with regard to the identification of specific mechanisms" (p. 578). Several studies suggest health behaviors or risky behaviors, as mechanisms for the observed education-health gradient. Risky health behavior such as smoking, physical inactivity, bad dietary habits and alcohol consumption are found to adversely affect health (e.g., Cawley and Ruhm 2012). However, health behaviors do not fully explain the relationship between education and health. Therefore, there must be other underlying mechanisms such as cognitive skills or labor market conditions (e.g., Cutler and Lleras-Muney, 2006; Lochner, 2011; and Schneider and Beblo 2010, for Germany).

In this paper, we analyze a different mechanism for the relationship between education and health: occupational demands. We consider ergonomic, environmental, psychical, social and time occupational demands. Ergonomic demands, such as working in a standing position, and environmental demands, such as working with dangerous substances are considered to be physical demands. Apart from that, psychical demands (e.g. working under pressure), social demands (e.g. being supported by colleagues) and time demands (e.g. working in shifts), are types of psychosocial demands. We assume that these demands are the same for workers with the same gender and age within occupations at a 2-digit level occupational code. ${ }^{1}$ Previous studies have shown that educational level is related to occupational demands (e.g., Monden 2005). As different physical and psychosocial demands are related to health as well (e.g., Fletcher et al. 2011), these occupational demands can serve as a mechanism to account for the relationship between education and health.

There is already some literature which analyzes the possibility that physical and psychosocial occupational demands could be an explanation for the relationship between socio-economic status in general and health. However, most of these studies either focus on a small subgroup of the population (Brand et al. 2007 and Warren et al. 2004 for high school graduates; Sekine et al. 2009 for civil servants) or focus on socio-economic position more in general (Kaikkonen et al. 2009; Niedhammer et al. 2008). We contribute to the

\footnotetext{
${ }^{1}$ We use the German classification of occupations, "Klassifizierung der Berufe 1992" (KldB), which is comparable to the ISCO codes.
} 
literature in three ways. First, we analyze the extent to which different physical and psychosocial occupational demands play a role in explaining the relationship between education and health for a representative sample of the entire working population. We use a combined measure of education that distinguishes between different educational levels on the one hand (primary to tertiary) and the type of educational degree on the other hand (general versus vocational), which matches the features of the German educational system better. Second, we extend the literature by analyzing not only workers' health status but their health behavior as well. More precisely, we focus on subjective health status, BMI and smoking status. Third, we include both employed and no longer employed ${ }^{2}$ people in our analyses, whereas previous studies mostly focused on the working population only. For the no longer employed, we use characteristics of their former occupation. This has the advantage that we do not exclude people who might potentially already have left the workforce (by becoming long-term sick, unemployed or by taking early retirement) due to adverse occupational demands.

To analyze the question to what extent occupational demands can explain the relationship between education and health, we merge the German Microcensus data with the German Employment Survey. The German Microcensus data are unique in the sense that they cover a large representative sample of the German population (1\%). The Microcensus includes information on various topics such as demographics as well as detailed information on the respondent's education, occupation and health. Based on the occupation individuals work(ed) in, we can match this dataset with information derived from the German Employment Survey. This dataset is constructed to get more insights into the job tasks and demands of the German population. Thus, the German Employment Survey makes it possible to construct different physical and psychosocial occupational demand indices (cf. Kroll 2011). Even though the combination of these two datasets does not allow for causal interpretations, it does provide us with a unique dataset that enables mediating analyses on the role of occupational demands in explaining the relationship between education and health.

We find that whereas occupational demands do not explain educational differences in subjective health status, they do partially mediate the education gradient in the considered health behaviors. Educational differences in smoking status can partly be explained by ergonomic, environmental, psychical and social demands. The educational gradient in BMI is partly attributable to social occupational demands. Time demands play no role in mediating the relationship between education and health or health behaviors. Moreover, our analyses show that occupational demands (apart from psychical demands) are more strongly related to health for people who are no longer active in the labor market. We even find that a longer time span since leaving the active labor market implies a stronger relationship between ergonomic, environmental

\footnotetext{
2 These people are entitled "no longer employed" to distinguish them from the unemployed, who form only a part of this group. "No longer employed individuals" are those individuals who are not employed in 2009 but have worked in the past and are at the age of 25-65 years. However, the no longer employed might reenter the labor market after 2009, which we do not observe.
} 
and social demands in the last occupation and current health. This suggests that high occupational demands increase the probability that individuals will become unemployed or inactive (due to sickness).

The outline of the paper is as follows: In Section 2, we situate our paper in the context of the existing literature. The dataset, the construction of the occupational demand indices and some summary statistics are described in Section 3. In Section 4, we report on the empirical approach with regard to the mediation analysis. In Section 5, we report and discuss our findings. The final Section concludes.

\section{Related Literature}

A first requirement for occupational demands to be a potential mediator in the relationship between education and health is that education and occupational demands are related. Occupational requirements are often related to both the level and field of education. For example, one needs a medical diploma (a master's degree at least) to become a general practitioner. The relationship between education and occupational demands has been confirmed by a number of studies. Monden (2005) focused on educational differences in lifetime exposure to adverse working conditions (retrospective) and found a negative relationship between years of education and bad working conditions. Borg and Kristensen (2000) found that whereas a lower the social class is related to worse environmental exposures, such as chemical or ergonomic conditions, for some psychosocial working conditions, such as psychological demands, the opposite relationship was found. In other words, those from a lower social class experience lower psychosocial working conditions than those from a higher social class. This suggests heterogeneity in the relationship between education and working conditions across the type of working conditions.

A second requirement is that occupations, or more specifically occupational demands, are related to health. Several studies have shown that there indeed is a relationship between occupations and health. Some studies found a faster deterioration in health for manual workers (e.g., Morefield 2011; Choo and Denny 2006). While differences in health between occupational statuses have been well explored, only a few studies put emphasis on more disaggregated occupational groups that operationalize job characteristics rather than social prestige, which is what using occupational status does. One reason might be that such analyses require rich data containing enough observations per occupational group to achieve reliable results. A US-American longitudinal study by Johnson et al. (1999) looked at 69 different occupational groups to investigate differences in mortality risks and found that the higher the intensity of work and the less qualified the work, the higher the mortality risk of an occupational group. In this study, we include occupational demands on a low aggregation level (2 digit) to analyze the relationship between occupational demands and workers' health.

According to this previous literature, occupational demands may indeed explain the relationship between education and health. Nevertheless, most studies do not deal with education per se, but analyze the mediating role of occupations or occupational demands between socio-economic status and health. Warren et al. (2004), 
as well as the extended analysis of this study by Brand et al. (2007), found that occupational demands, measured by physical and psychosocial demand indices, play an important role in mediating the associations between socio-economic status and self-assessed health, cardiovascular and musculoskeletal problems. However, as they only considered high school graduates, generalization of their findings is scarcely possible. A different study investigated the link between occupational demands and socioeconomic inequalities in the incidence of myocardial infarction (Huisman et al. 2008). This study found that job control and adverse physical working conditions provide a partial explanation of this link. Interestingly, job control turned out to be the only psychosocial demand that was significantly related to myocardial infarct, though the researchers considered numerous other psychosocial demands. Lahelma et al. (2004) found that occupational class mediates the relationship between education and health only to a very small extent. Using French data, Niedhammer et al. (2008) found that ergonomic, physical and chemical exposures, measured by expert evaluations, as well as self-perceived decision latitude, reduce the occupational class differences in health by 24$58 \%$. However, they did not find that any other self-perceived psychological demand contributed. As most of these studies focus on a small subgroup of the population only, we contribute to this literature by focusing on a representative sample of the entire working population.

Although there are some other studies that analyze the mediating role of occupational characteristics in the relationship between socio-economic status and health, only a few analyze the mediating role of occupations or occupational demands in the relationship between education and health. Most studies include occupational dummies and thereby make it harder to identify what the exact mechanism is. We are aware of only a very few studies that analyze the mediating role of occupations in explaining the relationship between education and health. Cutler and Lleras-Muney (2006) simply controlled for occupation and industry dummies in longitudinal data and did not find that occupations can be the main mechanism by which a higher education relates to better health. Case and Deaton (2003) also included occupational dummies in their regression of education on health. Including 16 different occupational groups, they found that effects of education are reduced though not eliminated by controlling for occupation. They concluded that lower-paid work in manual occupational groups impairs self-rated health much higher and in addition self-rated health in these groups worsens even faster with time. However, from their study, it remains unclear what occupational characteristics are responsible for the mediating effect they identified. Three studies explicitly looked into the mediating role of occupational demands in explaining the relationship between education and health. However, these studies often focused on a subgroup of the population, thereby reducing the generalizability of their findings. Focusing on a sample of high school graduates only, Brand et al. (2007) analyzed the role of physical and psychosocial job characteristics in explaining the relationship between the probability of a completed college education and health. They found that the occupational demand indices used account for some or all of the associations between education and health, depending on the health outcome considered. Monden (2005) investigated the mediating role of lifetime exposure to different physical and psychosocial working conditions in the relationship between education and subjective health for the Dutch population. 
Taking retrospective information, he found that lifetime exposure to adverse working conditions explains about one third of educational differences in subjective health for men but only a small percentage for women. In addition to Monden (2005), we include also the non-working population, as a history of working in occupations with adverse occupational demands could lead to unemployment or early retirement due to poor health. Moreover, we extend Monden's research by focusing not only on subjective health, but on health behavior as well.

Several pathways for how occupational demands might operate as mediators in the education-health relationship are conceivable. For physical demands it is likely that the lower educated choose or depend on jobs with poor working conditions, which could affect workers health directly due to attrition or accidents. Moreover, it is also possible that physical demands promote unhealthy behaviors. People working in physically demanding occupations are likely to have an increased need for brief periods of rest during the working day. Smoking could be used as an excuse for taking such short breaks (Albertsen et al. 2004). In addition, smoking breaks could be culturally-rooted, especially in manual occupations. As a result, peer effects are likely to occur, as workers might be more inclined to smoke or also eat if their co-workers do so. Unlike physical demands, psychosocial demands are likely to occur both in low-skill and high-skill occupations. While the lower educated could experience psychosocial demands such as a small degree of autonomy at work, the higher educated are more likely to experience a different kind of psychosocial demands, e.g. often being given new tasks or having to work overtime. Both could be perceived as stressful, and it is therefore not a priori clear how education might be related to psychosocial demands. However, compared to high-educated workers, it is possible that the low-educated workers have a lower level of (health) knowledge and poorer coping strategies to deal with psychosocial demands, e.g. time pressure or lack of social support. In turn, this could influence their health behaviors, as smoking or excessive eating could serve to compensate for such stressful demands.

\section{Data and Summary Statistics}

The data we use to analyze the relationship between the level of education, occupational demands and health are based on two sources. First, we use individual-level data from the German Microcensus (2009), an annual administrative census on the living situation covering approximately $1 \%$ of the German population with 
interviews imposing a duty of disclosure. ${ }^{3}$ Second, we use the German Employment Survey (2005/2006), from which we construct indices for occupational demands ${ }^{4}$.

The German Microsensus has a large number of observations, and is therefore adequate for analyses considering subgroups, such as occupations, comprising enough people even in rare occupations. In addition, the sample from 2009 offers the latest available information on health-related questions as the Microcensus contains an add-on module on health only every four years. Whereas the participation in the Microcensus is inherently mandatory, sensitive questions, such as those about a respondent's health and health behavior, are voluntary and therefore non-response-rates on these items occur in a range from $18-25 \% .5$

We restrict the analyses to people aged 25-65 in order to concentrate on the working-age population and those likely to have completed their education. Additionally, people with non-valid data on actual and former occupations are excluded and only people living in private households which are their main residence are considered in order to avoid some individuals being counted twice. Overall our final sample consists of 359,587 individuals.

In this study self-assessed health status and health behaviors are considered as outcomes of interest. The question on health status (Have you been ill or injured during the last four weeks?') is translated into a dichotomous variable ("bad health") taking the value 1 if the respondent has been in bad health during the last four weeks and 0 if not. Measures of health behavior are smoking status and body mass index (BMI) ${ }^{7}$, as smoking and obesity are the dominating behavioral factors that promote various health problems and even death. Smoking status is used as an indicator variable ("smoker"), taking the value 1 if the respondent currently occasionally or regularly smokes and 0 if not. BMI is calculated by the common formula (weight in $\mathrm{kg} / \mathrm{height}$ in

\footnotetext{
${ }^{3}$ Due to the cross-sectional design of the data used, it is not possible to consider cumulative exposure to work factors which could be important if persistent occupational demands affect health in the long term to a greater extent (see Fletcher et al. 2011 or Monden 2005). As there is no detailed information on work history in the database, we are not able to consider job transitions which might occur due to harmful occupational demands. Nevertheless, we are able to include retrospective information on unemployed and inactive people on about their former occupation and therefore mitigate the selection problem that the working population is per se healthier as they are healthy enough to work.

${ }^{4}$ The German Employment Survey 2006 also includes information on subjective health status and education. However, information on health behavior is not included in this Survey. Moreover, the German Employment survey does not allow analyses at the 2-digit occupational level as the sample size is too small. Therefore, we base our main analyses on the German Microcensus 2009, which is a large dataset that includes information on health behavior and contains enough observations by 2-digit occupational groups.

${ }^{5}$ Non-response analyses indicate that higher educated, married individuals living in Eastern Germany have a slightly lower probability of answering the health questions.

${ }^{6}$ It has to be considered, that this specific question rather captures short-term illnesses during the last month rather than long-term or chronic diseases which are probably not captured by this health measure.

7 There are limitations with the measurement of these health outcomes as they are based on self-reported data and the results could suffer from measurement error. Measured BMI is generally higher than self-reported (Cawley 2004). Thus, BMI as well as smoking could typically underestimated for example due to social desirability.
} 
$\mathrm{m}^{2}$ ), using self-reported height and weight and considered as a continuous outcome in the analyses ${ }^{8}$. Although BMI is only an indirect measure of health behavior, as a proxy for nutrition behavior and physical activity it is commonly used as an indicator for future health or risky health behavior (e.g. Jürges et al. 2009).

As the Microcensus contains separate information on the highest school and vocational qualification, a combined variable considering both educational level and the type of educational degree (general versus vocational) is constructed according to the CASMIN-Classification. The CASMIN-Classification is one of the most frequently applied instruments to measure education in an international comparative sense (Brauns et al. 2003). Education is therefore classified into eight different stages: primary education (if the respondent has not completed any kind of secondary schooling), lower, intermediate and upper secondary education each with information on the completion of any kind of vocational training (voc) or not (gen) and tertiary education. In all the analyses, education is included as a categorical instead of a continuous variable in order to better understand the relationship between education and health and the possible mediating effect of occupational demands, and to determine whether returns to schooling are similar for every level or whether some levels of education are even more strongly related to health (Cutler and Lleras-Muney 2006).

There is no information on physical and psychosocial working conditions within the Microcensus. We follow Kroll (2011) in proxying occupational demands by constructing indices via multilevel regressions from the German Employment Survey. Via occupational codes, the indices (separate for each gender and age group) are matched to the Microsensus. Both datasets are representative for the German working population. ${ }^{9}$

The German Employment Survey (2006) is a representative labor force cross-section on qualification and detailed working conditions in Germany covering 20,000 employees. The Employment Survey was conducted jointly by the German Federal Institute for Vocational Education and Training (BIBB) and the German Federal Institute for Occupational Safety and Health (BAuA) and included employed people working at least 10 hours per week and remunerated (Hartmann 2006). Similar to the Microcensus, we restrict the construction of the occupational demand indices to employees aged 25-65. The sample on which the occupational demands are based therefore consists of 18,797 individuals.

In contrast to the Employment Survey 2006, we focus not only on people currently working according to the Microcensus 2009. If people did not state a current occupation for one or more of several reasons, such

\footnotetext{
${ }^{8} \mathrm{BMI}$ as a measure of overweight is often criticized due to the fact that muscle mass leads to a higher BMI and therefore does not serve as a proxy for overweight. As a robustness check, we calculated probit models with marginal effects for the indicator variable obese (BMI $>=30)$ and not obese. This yields similar results.

${ }^{9}$ For the employed people in our sample, we have to assume that occupational demands did not substantially change in the years between the dates of the two surveys were hold (2006 and 2009). Unfortunately, the German Employment Survey provides data on occupational characteristics for 2006 only and there are no comparable German data containing such detailed information on occupational demands for past years. For those no longer employed in 2009, we have to assume that occupational demands have not changed significantly since they have left their jobs. The average time span between 2009 and withdrawal from the labor market is 7.8 years for the sample of no-longer employed people.
} 
as unemployment or (early) retirement, the last occupation is taken instead, assuming that former working conditions affect current health. We do so because there could be a non-random selection of workers who have left the active labor market because occupational demands negatively affect their health and they are no longer able to work. The workers in the Microsensus might therefore be a positive selection of people, the so-called healthy worker effect (McMichael et al. 1974). Hence, we construct a continuous variable that indicates how many years have elapsed since the respondent hast left his/her last occupation. This variable equals 0 if the respondent is currently employed and therefore data on his/her current occupation are available to control for in the analyses. People without information on their last or current occupation are excluded. ${ }^{10}$ Occupation is measured by the classification of professions (1992) of the German Federal Employment Agency's (KldB92) 2-digit codes, distinguishing 88 different occupational groups. This classification is very similar to the International Standard Classification of Occupations (ISCO) but structures occupation more adequately for the German labor market.

Additionally, we include the following control variables in all our regressions: gender, age, (age/10) ${ }^{2}$, marital status, region (West vs. East Germany) and the number of hours usually worked by the respondent per week.

Overall, both samples are fairly similar distributed with regard to the main variables considered in this study (see Table A1 in the Appendix). The distribution of education, measured via CASMIN, differs slightly in the two data sources, as the better educated are somewhat overrepresented in the Employment Survey. The share of individuals without a vocational degree (referred to as general education) declines with rising educational level in both samples. Some further differences, e.g. in age and gender, occur due to the fact that no longer employed individuals are included in the Microcensus but not in the Employment Survey.

\subsection{Construction of the Occupational Demands}

Our way to measure occupational demands deviates from the way that is common in occupational epidemiological research, namely calculating a so called Job Exposure Matrices (JEM) by taking occupation-specific means. However, this method is problematic, as it implicitly assumes that the observed characteristics result from the features of the occupation only and that there are no other important differences between the workers. Thereby, group and individual effects on the outcomes cannot be disentangled (Kroll 2011). Our method is also different from previous cross-sectional research on mediating effects of occupational demands in the education-health relationship, which mainly takes individual assessments of occupational demands (e.g. Warren et al., 2004; Monden, 2005). That way, personal characteristics rather than objective occupational demands might be captured in the measure of occupational demands. We therefore pursue

\footnotetext{
10 This concerns 9,649 people who have either never worked or did not report valid information on their occupation.
} 
another approach and suppose that occupational demands themselves are mainly driven by differences in occupations, age, working hours per week and gender.

We build on Kroll (2011) by performing a multilevel analysis with random intercepts to generate occupationspecific demands. This strategy yields more robust occupational demands for small occupations than the commonly used JEM do. Contrary to Kroll, we consider each of the five categories separately - ergonomic, environmental, psychical, social and time demands - instead of adding these categories to a physical and psychosocial index. Thus, occupational demands are included in a more detailed way to avoid aggregation bias, as each of them might be differently correlated with education and health. ${ }^{11}$

Following Kroll (2011), the procedure of generating the five demand indices contains several steps. First the 39 single items (see Table A2 in the Appendix) collected in the Employment Survey 2006 are dichotomized (having harmful demand often vs. never, seldom, sometimes), assigned to five categories (ergonomic, environmental, social, psychical and time demands) and added to an individual sum score for each of the five categories. As some conditions are health enhancing, e.g. arranging work in own schedule and all social demands, the labels are interchanged (never vs. seldom, sometimes, often). Finally, the five individual indices - ergonomic, environmental, psychical, social and time occupational demands - are taken as outcome variables for the random intercept model to calculate the final indices by adjusting for the interceding variables gender, age and working hours. In Equation (1), the model is written down formally:

$$
Y_{i . j}=\beta_{o}+u_{0 j}+\beta_{x} X_{i}+\epsilon_{i j} \quad i=1, \ldots, n \quad j=1,2,3
$$

In which $Y_{i . j}$ denotes a specific type of occupational demands of individual $i$ in occupational level $j$. Multilevel regressions with random intercepts cope with the nested structure of data - here individuals nested within occupations - by dividing the overall error term in one separate random error term per level (indicated by subscript $j$ ). Following Kroll 2011, we exploit the full hierarchical structure of the occupational classification (KldB) by considering three levels (indicated by subscript $)$ ): the 2-digit (86 different groups), 3-digit (369 groups) and 4-digit $(2,287)$. The occupational level specific intercepts $\left(u_{1}, u_{2}, u_{3}\right)$ represent unobserved heterogeneity across each occupational level. Thus, the overall variance of occupational demands is separated into variation that is attributable to 2 -digit occupation-specific characteristics, variance that is attributable to differences between 3-digit occupations, variance that can be ascribed to the 4-digit occupations and finally the residual variance that is attributable to other, individual-specific characteristics (Rabe-Hesketh and Skrondal 2012). Therefore, it is assumed that occupational demands arise from the sum of parameters for overall job demand $\left(\beta_{o}\right)$, the occupational group specific demand on the level of KldB 2-digit, 3-digit

\footnotetext{
11 There are some more differences between Kroll's (2011) approach and ours: job tenure is not included as covariate because there is no information on it in Microcensus. Additionally, in contrast to Kroll (2011), we include the control variables in categories.
} 
and 4-digit $\left(u_{0 j}\right)$, a vector of covariates including gender eight age dummies, five dummies for the usual number of working hours per week $\left(\beta X_{i}\right)$ and the individual error term $\left(\epsilon_{i j}\right)$.

To assess the proportion to which the total variance in occupational demands can be ascribed to the different occupations in their different levels, variances belonging to the different levels and consequential the intra-class correlations are reported. Intra-class correlations represent the within cluster correlation, i.e. the share of variance attributable to the occupational level that ranges from 0 if the grouping conveys no information to 1 if all members of a group are identical.

The five multilevel predicted demand indices are merged by gender, 8 age group dummies ${ }^{12}$ and 86 occupations (KldB 2-digit) with the Microcensus. ${ }^{13,14}$ That is to extend the variation because occupational demands not only differ by occupations but also by gender and age and the data offers enough cases, i.e. there is one separate value for each combination $(1,376)$ of the merge variables (subsequently denoted by the subscript j). For a better interpretation and a better comparability among each other the occupational demand indices are $\mathrm{z}$-standardized before merging.

As there is no information on the number of working hours in the respondent's former occupation and thus for the no longer employed individuals, we use imputation by taking the mean working hours per week via gender, age-group (when occupation was left) and the respondent's last occupational group.

Table 1 shows the results of the random intercept model predicting the five different occupational demand indices. ${ }^{15}$ Within occupational groups there are small gender-specific differences in occupational demands. Women suffer from higher ergonomic, psychical and social demands, whereas men are more often exposed to environmental and time occupational demands. The high intra-class correlations show that the physical and psychosocial occupational demands considered vary substantially between the different occupational groups. This especially applies for physical demands where about 39\% of the variance in ergonomic and environmental demands is attributable to differences between the occupations (KldB 2-digit). While the first occupational classification level (2-digit) explains a large part of the variation in occupational demands, only a smaller share of the variation is attributable to the other two included levels. Coherently, the variances of the most aggregated level also show the greatest absolute value. Especially ergonomic and environmental occupational demands vary substantially between occupations, to that extent, that the variation attributable

\footnotetext{
${ }^{12}$ For the no longer employed, occupational demand indices are merged via the age in which the respondent has left his/her occupation.

${ }^{13}$ Predicted values include the fixed and random part of the Random-Intercept Model.

${ }^{14}$ This approach is different to Kroll (2011) who classified occupations into deciles according to the occupational demands which leads to a loss of information and variation.

15 The results of Kroll (2011) differ marginally; presumably due to slightly different model specifications (see Section 4.1).
} 
to all levels is even greater $\left(52 \%{ }^{16}\right.$ and $\left.57 \%\right)$ than the residual variation, representing the variation on individual level. Differences in social and time occupational demands (15\% and 30\% respectively) can be ascribed to the occupational levels to a lower extent. Differences in psychical demands are merely attributable to occupational groups $(6 \%)$. This could be due to the fact that the nature of psychical demands is rather subjective than objective. On the whole, occupational demands - especially physical demands - vary considerably between occupations and thus utilizing multilevel regression seems appropriate.

\subsection{Descriptive Evidence}

Occupational demands can only play a mediating role when they are related to both workers' education level and to workers' health (behavior). Therefore, we report on these raw relationships here.

\section{Education and Occupational Demands}

Ergonomic, environmental and social demands clearly differ between educational groups (see Figure A1 in the Appendix). People with primary education report the highest ergonomic, environmental and social demands within their occupation. Moreover, a gradient is shown for these demands, i.e. the amount that people report to experience these demands is gradually declining with increasing educational level. People with tertiary education suffer least from these demands. An opposite pattern emerges with respect to psychical demands. People with tertiary education report to suffer most often from psychical demands while lower educated people report less psychical demands. ${ }^{17}$ Overall, the considered occupational demands are clearly related to education, except for time demands which do not follow a regular pattern.

\section{Occupational Demands and Health}

There is a positive relationship between the probability of being in bad health on the one hand, and environmental, ergonomic and social demands on the other hand at the occupational level (see Figure A2 in the Appendix). The correlation between time demands and the probability of being in bad health at the individual level is slightly negative and significant at the $5 \%$ level. An even stronger negative relationship is found between psychical demands and the probability of being in bad health.

With regard to BMI we observe a clear positive relationship between all types of occupational demands and BMI, apart from psychical demands at the occupational level (see Figure A3 in the Appendix). This implies that people who work in occupations that are more demanding have on average a higher BMI. This also

\footnotetext{
${ }^{16}$ This results when all intra-class correlations of the three different occupational levels are taken together: e.g. ergonomic demands: $0.394+0.0562+0.0644=0.515$.

${ }^{17}$ Qiu et al. (2012) also found that education is positively related to psychical work characteristics (such as challenge).
} 
holds for correlations at the individual level. People working in occupations with high psychical demands, report on average a lower BMI.18

The correlations between the occupational demands and the probability to smoke are much stronger than those for health status and BMI, both at the occupational as well as at the individual level (see Figure A4 in the Appendix). Again, we find a positive and significant correlation between smoking and all but one type of occupational demands. Especially ergonomic and environmental demands are strongly correlated with smoking. For psychical demands we find a negative correlation with the probability to smoke.

Overall, health behavior and health status are worse among individuals who are exposed to higher occupational demands. The strongest correlations are found for occupational demands and smoking status. Only for psychical demands we find the opposite: the higher the psychical demands, the better self-rated health and the lower BMI and smoking probabilities.

\section{Empirical Approach}

In this paper, we investigate the mediation effect of five different types of occupational demands in explaining the relationship between education and health. Whereas previous studies restrict their mediating analyses on (a small part of) the working population, we also include people who have worked before but are no longer doing so (though they are still part of the workforce). This expands the generalizability of our findings. Using characteristics of their former occupation and including a measure of the time left since they left their last employment, currently not working people are still part of our sample.

We follow the procedure suggested by Baron and Kenny (1986) to investigate if any of the considered occupational demand indices mediates the relationship between education and health or health behavior, respectively. We use Ordinary Least Squares (OLS) models for estimating Equations (2) - (5). $\cdot^{19}$

As described in Equation (2), we first estimate the raw relationship between the different educational levels (EDUC) and the health outcomes bad health, BMI and smoking status (HEALTH).

$$
\operatorname{HEALTH}_{i}=\gamma_{0}+\gamma_{1} E D U C+\gamma_{x} X_{i}+\omega_{i}
$$

\footnotetext{
18 It seems plausible that psychical occupational demands might be related to eating behavior and thus to BMI. However, the epidemiological empirical evidence is ambiguous (see e.g. Overgaard et al. 2004; Wardle et al. 2011 for an overview).

${ }^{19}$ We estimate linear probability models (LPM) for the indicator outcomes bad health and smoking status, as the descriptive analysis suggests that the relationship between the considered occupational demands and bad health and smoking status tends to be linear. As a robustness check we also estimated marginal effects of Probit Models for the binary outcomes smoking status and bad health in Equations (2), (4) and (5). As the results are very similar, we focus on the LPM results for the ease of interpretation. We use robust standard errors clustered at the occupation level (KldB 2-digit) in all models. In doing so, the aggregated data on occupational demands is taken into account to achieve reliable results regarding significance. Additionally, the estimates' significance levels get comparable across models. As intra-class correlations are very small, there is no need to perform multilevel analyses in this case, inferring that variations in health outcomes are negligibly attributable to occupations while occupational demands are included.
} 
The vector $X$ denotes the following control variables: gender, age, $(\text { age } / 10)^{2}$, marital status, region (Westvs. East-Germany), the number of hours usually worked by the respondent per week, and the number of years since the respondent has left his/her last occupation (if currently employed put equal to 0). Second, we estimate one of the conditions that have to be fulfilled when testing mediations: we regress ergonomic, environmental, psychical, social and time occupational demands on education to evaluate whether occupational demands are significantly related to different educational level dummies. The occupational demand indices (OCC DEMANDS) generated via the multilevel approach as described in Section 3.1 are used as dependent variables in Equation (2):

$$
\text { OCC DEMANDS }=\delta_{0}+\delta_{1} E D U C+\delta_{x} X_{i}+\zeta_{i}
$$

Third, we estimate the relationship between occupational demands and health which is the second condition that should hold for occupational demands to explain the relationship between education and health. We include interaction terms in Equation (4) between occupational demands and the number of years since the last occupation. This enables us to see whether occupational demands are differently related to health across people who are currently employed compared to people who are (temporarily) dropped out of employment.

$$
\text { HEALTH }_{i}=\eta_{0}+\eta_{2} \text { OCC DEMANDS }+\eta_{3} \text { OCC DEMANDS } \times \text { YEARS OCCUPATION }+\eta_{x} X_{i}+\psi_{i}
$$

Fourth, we estimate the mediating model in which health is explained by both education and occupational demands. ${ }^{20}$ Comparing $\gamma_{1}$ in Equation (2) and $\theta_{1}$ in Equation (5), shows whether and to what extent the inclusion of occupational demands the relationship between education and health explains.

HEALTH $_{i}=\theta_{0}+\theta_{1}$ EDUC $+\theta_{2}$ OCC DEMANDS $+\theta_{3}$ OCC DEMANDS $\times$ YEARS OCCUPATION $\theta_{x} X_{i}+\xi_{i}$

We estimate a set of model specifications: specifications in which we include each occupational demand separately, and a specification in which we include all five demands simultaneously.

\footnotetext{
${ }^{20}$ It has to be mentioned that there might be potential alternative mechanisms, e.g. that individuals sort themselves in certain occupations because of their health limitations. However, these mechanisms are not addressed in this paper and this approach should be considered in a descriptive sense instead. But a comprehensive explanation of causal mechanisms via mediators is very difficult to address even in experimental mediation analysis (Bullock et al. 2010, p.553). Biased estimates are likely to occur if the direct effect is mediated by more than one variable or if the independent and mediating variables are related. In order to reduce the resulting bias, randomized experiments are a viable solution. Yet, finding appropriate instruments that externally manipulate the independent (education) and mediating (occupational demands) variable is a difficult task. As these problems are not satisfactorily solved by standard statistical procedures, we do not claim any causal interpretations of our results.
} 


\section{Results}

\subsection{Requirements for the Mediation Analyses}

\section{Education and Health}

The results on the raw relationship between the different educational levels and the three health outcomes bad health, BMI and smoking status (Equation 2) are shown in Table 2. In line with previous studies, we find that education is significantly related to all of the three health outcomes, which is indicated by the significant F-values testing joint significance of all educational levels. In Column (1), the results for the probability of being in bad health are reported. We find that the five lowest educational levels are significantly and negatively related to bad health. This implies that compared to the reference group - tertiary educated individuals - people with lower levels of education, have a higher probability of reporting bad health. Compared to the reference group, individuals with primary education have a 7 percent-point higher probability of reporting bad health. There seems to be no significant difference in health perception between tertiary educated and upper secondary education.

In Column (2) and (3), results with respect to BMI and smoking status are reported. For these measures of health behavior, we find a significant relationship with all educational levels. For BMI, we even find an educational gradient up to upper secondary general education: the estimates are gradually declining with higher educational levels. The strongest relationship appears for primary educated individuals having a 2.6 $\mathrm{kg} / \mathrm{m}^{2}$ higher BMI than tertiary educated individuals (reference group). The highest probability of being a smoker can be found for lower general secondary educated individuals, who have on average a 31 percentpoint higher probability to smoke than their tertiary educated counterparts.

\section{Occupational Demands and Education}

Table 3 displays the results on the relationship between occupational demands and education. ${ }^{21}$ Except for time demands, all occupational demands are significantly related to education. Ergonomic, environmental and social demands are positively related to education. The lower educated work on average in occupations with more hazardous physical and social occupational demands compared to individuals who completed tertiary education. This finding is consistent with previous studies (e.g. Monden 2005). In line with the descriptive evidence discussed in Section 3.2, psychical demands are negatively related to education so that the education-gradient in occupational demands goes in the opposite direction compared to the other types of occupational demands. Tertiary educated individuals experience higher psychical demands. In Column

\footnotetext{
${ }^{21}$ We also performed these analyses within the original data derived from the Employment Survey 2006, distinguishing between standardized individual sum scores. On the whole, the results within the Microcensus 2009 are similar to those within the Employment Survey. As we perform mediation analyses within the Microcensus, we present these results here.
} 
(5), we observe that time demands are not significantly related to any of the educational levels. This is in line with the descriptive analysis discussed in Section 3.2.

\section{Occupational Demands and Health}

In Tables 4-6, we report the findings of the relationship between our health measures and the measures for occupational demands. In Table 4, the results with respect to the probability of being in bad health are reported. Apart from time demands all types of occupational demands are at least at the 5\% significance level related to the probability of being in bad health. The estimates of environmental, ergonomic and social demands are positive, i.e. the higher the occupational demand, the higher the probability to be in bad health. The described findings between ergonomic and environmental occupational demands and the probability of being in bad health are found for both, the currently employed and for the no longer employed individuals in the sample. We even find that the longer the time span since leaving the last occupation, the stronger the relationship between the occupational demands and current health status is. This is shown by the significant and positive interaction terms in combination with the $\mathrm{F}$ tests on joint significance in Table 4 and suggests that people might have quit their jobs for health reasons due to hazardous occupational demands. In line with the descriptive evidence, psychical demands are negatively correlated with bad health for currently employed workers. This indicates that a higher psychical demand is related to better health. We find no significant relationship for people who are no longer employed. Neither do we find a significant relationship between social demands in the occupation and someone's health status. In Column (6), all demands are included simultaneously. The F test shows that the five occupational demands are together significantly related to bad health.

Similar to bad health, ergonomic, environmental, psychical and social demands are significantly related to BMI (Table 5) and the probability of being a smoker (Table 6). Apart from psychical demands, the point estimates are positive and thus indicate that BMI and the probability to be a smoker rise with increasing occupational demands. Of all significantly related demands, social demands are most strongly related to BMI for employed people: a one standard deviation higher social demands is related to a $0.5 \mathrm{~kg} / \mathrm{m}^{2}$ higher BMI. Otherwise, the probability that employed people smoke is mainly related to environmental demands. A one standard deviation increase in environmental demands are related to a 6.5 percentage point higher probability to smoke. We find that the relationships between ergonomic and social occupational demands and BMI are even stronger for the no longer employed people. The smoking status of no longer employed people is on average less strongly related to social occupational demands than for the currently employed workers. In the opposite, for psychical and time demands, we find that the relationship with the probability to smoke is stronger for the no longer employed than the employed. 
When all demands are included simultaneously (Column 6 in both Table 5 and 6 ), the correlation between health behavior and social demands is most profound. This suggests that social demands play a major role in explaining health behavior.

\subsection{Mediating Role of Occupational Demands}

We finally analyze to what extent the different occupational demands mediate the education-health and education-health-behavior relationships (Equation 5) and Tables 7-9 report on the results. The first Column of each of the three tables displays the relationship between the educational level and each health outcome and is thus equivalent to the results presented in Table 2 (Equation 2). Thereby, education coefficients in the first Column serve as direct comparison for the education estimates of the models that additionally include occupational demands (Columns 2-7). Related percentage changes, $t$-values for significant differences and figures illustrating the changes in the education estimates are included in the Appendix (Tables A3-A5; Figures A5-A7).22

\section{Bad Health}

As we have already seen, only primary, lower and intermediate secondary education are significantly related to bad health (Table 7). If at all, occupational demands can only mediate the relationship between these educational levels and the probability to be in bad health. We find that only the estimate for lower secondary general education reduces significantly by $25 \%$ when social demands are included while none of the other estimates reduces significantly (cf. Table A3, Figure A5). Additionally, the tests on joint significance of all educational dummies on bad health are significant no matter which types of occupational demands are included. Therefore, we conclude that occupational demands do not mediate the relationship between education and bad health. This can be explained by looking into the coefficients on occupational demands. Whereas occupational demands are significantly related to the probability of being in bad health in the models in which educational dummies were left out (Table 4), they are no longer significant when educational dummies are included (except for time demands). Interestingly enough, for the no longer employed people in our sample, we actually do find a significant relationship between the occupational demands in their last job and their health status at least for ergonomic, environmental and time demands.

\section{$B M I$}

Contrary to bad health, BMI is significantly related to all levels of education (Table 8). Even after including occupational demands, education remains significantly related to BMI. The individual education coefficients slightly reduce when ergonomic, environmental and psychical demands are included, although these reductions turn out to be non-significant (cf. Table A4, Figure A6). This is in contrast to our findings with respect

\footnotetext{
22 The percentage changes of the education-coefficients result from the formula $\frac{\beta_{\text {new }}-\beta_{\text {old }}}{\beta_{\text {old }}} \times 100$, t-values are calculated by $\frac{\beta_{\text {old }}-\beta_{\text {new }}}{S E_{\text {new }}}$, see Appendix Tables A3-A5 and Figures A5-A7).
} 
to social demands. Education coefficients are reduced in the range of 15 to $20 \%$ when social demands are included. ${ }^{23}$ For the lower four educational levels (primary to intermediate secondary general education) these reductions turn out to be significant. Furthermore, the estimates in these educational levels also reduce significantly (16-21\%) when all occupational demands are included simultaneously (Table 8, Column 7).

\section{Smoking Status}

Similar to BMI, education is significantly related to the probability to smoke across all levels (Table 9). But again, educational estimates on smoking status remain significant on a $0.1 \%$ level even if occupational demands are included. Additionally, the F-tests on joint significance of all educational dummies remains significant. Even though all education coefficients remain significantly related to the probability to smoke, the size of the correlation decreases significantly (cf. Table A5, Figure A7). Especially the coefficients for the lower educational levels decrease substantially. Including ergonomic demands, for example, significantly reduces the coefficient on primary education by roughly $16 \%$ (e.g. from 0.244 to 0.204 ). Environmental demands even draw a clearer picture by reducing four of the educational coefficients significantly and to an even larger extent. The impact of primary education on the probability to smoke is reduced by $17 \%$ when environmental demands are included. Moreover, for lower secondary educated individuals the reduction in the education coefficients attributable to environmental demands is about $13-14 \%$. Whereas reductions in the education estimates turn out to be significant for lower secondary educated only (8-9\%) when psychical demands are included, social demands seem to mediate the education-smoking-relationship to a greater extent. Those differences make about $18 \%$ for the primary educated individuals in comparison to tertiary educated and about $12-13 \%$ for the following three educational levels (Column 5). When all demands are included simultaneously, reductions in the education estimates are significant for all educational levels except for the upper secondary vocational level. The estimate for primary educated reduces the most by $27 \%$ (from 0.244 to 0.179$)$.

Overall, we can conclude that the relationship between education and health behavior can partly be explained by occupational demands. Especially, ergonomic, environmental and social demands are important occupational demands that mediate the education-health behavior-relationship. We find no evidence for occupational demands to explain the relationship between education and subjective health status.

\section{Conclusion}

The aim of the paper is to analyze potential mediating effects of ergonomic, environmental, psychical, social and time occupational demands in the relationship between education on the one hand, and subjective

\footnotetext{
${ }^{23}$ One exception is "upper secondary general" education where estimates reduce up to $40 \%$ (social demands), though not significantly.
} 
health and health behavior on the other. Our first contribution is that we focus on the role of five specific occupational demands: ergonomic, environmental, psychical, social and time demands, whereas most studies include either occupational dummies or only differentiate between physical and psychosocial demands. Our second contribution is that we do not solely look into the mediating role of occupational demands between education and subjective health, but also into the mediating role of occupational demands in the relationship between education and health behavior. In this context, we analyze BMI and smoking status. Our third contribution is that we extend the analyses by focusing on a broad sample. We include the whole working population (instead of a subgroup of for example high educated workers) and additionally include people who no longer actively participate in the labor market. Thereby, we analyze whether people who used to work in demanding occupations have a lower probability of still being employed, which could be related to their health status as well.

We can summarize our main findings as follows. First, we find that the lower educated have on average higher and hazardous ergonomic, environmental and social occupational demands compared to individuals with a higher educational qualification. In opposite, higher educated individuals tend to suffer from higher psychical demands more often. Time occupational demands are not significantly related to education at all. Apart from time demands, the considered occupational demands also turn out to be significantly related to the probability of being in bad health, to the probability to smoke and to BMI. On average, the relationships between occupational demands and health (behavior) turn out to be even stronger for those individuals who are no longer employed. This suggests that working in demanding occupations increases the probability of leaving the active workforce.

Second, we find that occupational demands play a role in explaining the relationship between education and health behavior, especially for low and intermediate educated individuals. Education coefficients on BMI and smoking status significantly reduce up to $27 \%$ when all occupational demands are included. The relationship between education and BMI is partly explained by occupation-specific social demands, whereas the relationship between education and smoking status is partly explained by social, ergonomic and environmental demands. We do not find evidence that the considered occupational demands explain the relationship between education and bad health. This is in contrast to previous studies which focused on the working population (Niedhammer et al. 2008) or high-school graduates (Warren et al. 2004) only. They found that socio-economic differences in subjective health status were reduced to a greater extent when controlling for physical work factors. Even though our analyses do not allow for causal interpretation on the effect of education on health, our mediation analyses show that occupational demands partly explain the correlation between education and health. 
Our study shows that it is important to take the entire working population and even the no longer employed into account, when analyzing the mediating factors of the relationship between education and health. Moreover, our study reveals research opportunities for analyzing the role of occupational demands in explaining the outflow of (older) workers out of the active labor market into early-retirement and long-term sickness. This is an important issue also for policy makers in the context of raising the retirement age in most European countries.

\section{References}

Albertsen, K., Hannerz, H., Borg;,V., Burr, H., 2004. Work environment and smoking cessation over a fiveyear period. Scandinavian Journal of Public Health 32 (3), 164-171.

Baron, R.M., Kenny, D.A., 1986. The moderator-mediator variable distinction in social psychological research: Conceptual, strategic, and statistical considerations. Journal of Personality and Social Psychology 51 (6), 1173-1182.

Borg, V., Kristensen, T.S., 2000. Social class and self-rated health: can the gradient be explained by differences in life style or work environment? Social Science \& Medicine 59 (7), 1019-1030.

Brand, J.E., Warren, J.R., Carayon, P., Hoonakker, P., 2007. Do job characteristics mediate the relationship between SES and health? Evidence from sibling models. Social Science Research 36 (1), 222-253.

Brauns H., Scherer, S., Steinmann, S., 2003. The CASMIN educational classification in international comparative research. In: Wolf, C., Hoffmeyer-Zlotnik, J.H.P. (Ed.), Advances in Cross-National Comparison. A European Working Book for Demographic and Socio-economic Variables. Kluwer, 221-224.

Brunello, G., Fort, M., Schneeweis, N.E., Winter-Ebmer, R., 2011. The Causal Effect of Education on Health: What is the Role of Health Behaviors? IZA discussion paper No 5944.

Bullock, J.G, Green, D.P., Ha, S.E., 2010. Yes, but what's the mechanism? (Don't expect an easy answer). Journal of Personality and Social Psychology 98 (4), 550-558.

Case, A., Deaton, A.S., 2003. Broken down by work and sex: How our health declines. National Bureau of Economic Research, Working Paper Series No 9821.

Cawley, J., 2004, The Impact of Obesity on Wages. Journal of Human Resources XXXIX (2), 451-474.

Cawley, J., Ruhm, C.J., 2012. Chapter 3, The Economics of Risky Health Behaviors. In: Pauly, M.V., McGuire, T.G., Barros, P.P. (Ed.), Handbook of Health Economic, Volume 2, Elsevier.

Choo, E., Denny, M., 2006. Wearing Out - The Decline in Health. Working Papers, University of Toronto, Department of Economics, http://EconPapers.repec.org/RePEc:tor:tecipa:tecipa-258.

Cutler D.M, Lleras-Muney, A., 2006. Education and Health: Evaluating Theories and Evidence. National Bureau of Economic Research, Working Paper Series No 12352.

Employment Survey, 2006. Scientific Use File provided by the gesis-Institute for Social Science. Data conducted jointly by the Federal Institute for Vocational Education and Training (BIBB) and the Federal Institute for Occupational Safety and Health (BAuA).

Fletcher, J. M., Sindelar, J. L., Yamaguchi, S., 2011. Cumulative effects of job characteristics on health. Health Economics 20 (5), 553-570.

Grossman, M., 2006. Chapter 10, Education and Nonmarket Outcomes. In: Hanushek, E., Welch, F. (Ed), Handbook of the Economics of Education, Elsevier, 577-633.

Hartmann, J., 2006. BIBB/BAuA-Erwerbstätigenbefragung 2005/2006 Feldbericht. München: TNS Infratest Sozialforschung. 
Huisman, M., Van Lenthe, F., Avendano, M., Mackenbach, J., 2008. The contribution of job characteristics to socioeconomic inequalities in incidence of myocardial infarction. Social Science \& Medicine 66 (11), $2240-2252$

Johnson, N.J., Sorlie, P.D., Backlund, E., 1999. The Impact of Specific Occupation on Mortality in the U.S. Longitudinal Mortality Study. Demography 36 (3), 355-367.

Jürges, H., Reinhold, S.; Salm, M., 2011. Does schooling affect health behavior? Evidence from the educational expansion in Western Germany. In: Economics of Education Review 30 (5): 862-872.

Kaikkonen, R., Rahkonen, O. Lallukka, T., Lahelma, E., 2009. Physical and psychosocial working conditions as explanations for occupational class inequalities in self-rated health. The European Journal of Public Health 19 (5), 458-463.

Kemptner, D., Jürges, H., Reinhold, S., 2011. Changes in compulsory schooling and the causal effect of education on health: Evidence from Germany. Journal of Health Economics 30 (2), 340-354.

Kroll, L.E., 2011. Konstruktion und Validierung eines allgemeinen Index für die Arbeitsbelastung in beruflichen Tätigkeiten auf Basis von ISCO-88 und KldB-92. Methoden — Daten — Analysen 5 (1), 63-90.

Lahelma, E., Martikainen, P., Laaksonen, M., Aittomäki, A., 2004. Pathways between socioeconomic determinants of health. Journal of Epidemiology and Community Health 58 (4), 327-332.

Lochner, L., 2011. Chapter 2, Nonproduction Benefits of Education: Crime, Health, and Good Citizenship. In: Hanushek, E., Machin, S., Woessmann, L. (Ed), Handbook of the Economics of Education, Volume 4, Elsevier, 183-282.

McMichael A.J., Spirats R., Kupper L.L., 1974. An epidemiological study of mortality within a cohort of rubber workers, 1964-72. Journal of Occupational Medicine 16 (7), 458-64.

Microcensus, 2009. On-Site Data analysis, Research Data Centres of the Federal Statistical Office and the Statistical Offices of the Länder.

Monden, C.W.S., 2005. Current and lifetime exposure to working conditions. Do they explain educational differences in subjective health? Social Science \& Medicine 60 (11), 2465-2476.

Morefield, G.B., Ribar, D.C., Ruhm, C.J., 2011. Occupational Status and Health Transitions. National Bureau of Economic Research Working Paper Series No 16794.

Niedhammer, I., Chastang, J. F., David, S., Kelleher, C., 2008. The contribution of occupational factors to social inequalities in health: findings from the national French SUMER survey. Social Science \& Medicine 67 (11), 1870-1881.

Overgaard, D., Gyntelberg, F., Heitmann, B.L., 2004. Psychological workload and body weight: Is there an association? A review of the literature. Occupational Medicine 54 (1), 35-41.

Qiu, H., Bures, R., Shehan, C. L., 2012. The inconsistent mediating effects of psychosocial work characteristics on the education-health relationship. Social Science \& Medicine 75 (8), 1539-1546.

Rabe-Hesketh, S., Skrondal, S., 2012. Multilevel and Longitudinal Modeling Using stata, 3rd Edition: StataCorp LP.

Schneider, J., Beblo, M., 2010. Health at work - indicators and determinants. A revised literature and data review for Germany. Institute for Employment Research, Nuremberg, Germany.

Sekine, M., Chandola, T., Martikainen, P., Marmot, M., Kagamimori, S., 2009. Socioeconomic inequalities in physical and mental functioning of British, Finnish, and Japanese civil servants: the role of job demand, control, and work hours. Social Science \& Medicine 69 (10), 1417-1425.

Wardle, J., Chida, Y., Gibson, E.L., Whitaker, K.L., Steptoe, A., 2011. Stress and Adiposity: A Meta-Analysis of Longitudinal Studies. Obesity 19 (4), 771-778.

Warren, J.R., Hoonakker, P., Carayon, P., Brand, J.E., 2004. Job characteristics as mediators in SES-health relationships. Social Science \& Medicine 59 (7), 1367-1378. 
Table 1: results from the random intercept model for generating occupational demand indices

\begin{tabular}{|c|c|c|c|c|c|c|}
\hline & & (1) & (2) & (3) & (4) & (5) \\
\hline & & ergonomic & environment & psychical & social & time \\
\hline \multirow{4}{*}{$\begin{array}{l}\frac{n}{0} \\
\text { : } \\
0 \\
0 \\
0\end{array}$} & female & $0.0448^{* *}$ & $-0.0610^{*}$ & $0.209^{* * *}$ & $0.170 * * *$ & $-0.223^{* * *}$ \\
\hline & & $(0.0142)$ & $(0.0255)$ & $(0.0392)$ & $(0.0198)$ & $(0.0237)$ \\
\hline & age group dummies & Yes & Yes & Yes & Yes & Yes \\
\hline & dummies for working hours & Yes & Yes & Yes & Yes & Yes \\
\hline \multirow{4}{*}{ 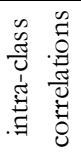 } & KldB_2-digit & 0.387 & 0.394 & 0.0223 & 0.105 & 0.131 \\
\hline & KldB_3-digit & 0.0977 & 0.0562 & 0.0138 & 0.0304 & 0.0890 \\
\hline & KldB_4-digit & 0.0828 & 0.0644 & 0.0239 & 0.0186 & 0.0764 \\
\hline & chi2 & 42.15 & 256.5 & 1410.8 & 155.7 & 3696.1 \\
\hline \multirow{6}{*}{ 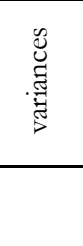 } & var KldB_2-digit & 0.447 & 1.321 & 0.0995 & 0.129 & 0.263 \\
\hline & var KldB_3-digit & 0.113 & 0.189 & 0.0616 & 0.0372 & 0.179 \\
\hline & var KldB_4-digit & 0.0954 & 0.216 & 0.107 & 0.0228 & 0.154 \\
\hline & var residual & 0.498 & 1.629 & 4.185 & 1.037 & 1.415 \\
\hline & & LL - 20951.1 & -31947.7 & -40357.3 & -27316.7 & -30541.4 \\
\hline & & N 18793 & 18793 & 18794 & 18791 & 18794 \\
\hline
\end{tabular}

Table 2: OLS-results of educational levels on health outcomes

\begin{tabular}{|c|c|c|c|}
\hline & $\begin{array}{c}\text { (1) } \\
\text { bad health }\end{array}$ & $\begin{array}{c}(2) \\
\text { BMI }\end{array}$ & $\begin{array}{c}(3) \\
\text { smoker }\end{array}$ \\
\hline \multirow[t]{2}{*}{ primary } & $0.0650^{* * *}$ & $2.648^{* * *}$ & $0.244^{* * *}$ \\
\hline & $(0.00677)$ & $(0.211)$ & $(0.0182)$ \\
\hline \multirow[t]{2}{*}{ lower secondary gen } & $0.0418^{* * *}$ & $2.276^{* * *}$ & $0.307^{* * *}$ \\
\hline & $(0.00529)$ & $(0.132)$ & $(0.0111)$ \\
\hline \multirow[t]{2}{*}{ lower secondary voc } & $0.0241 * * *$ & $1.660^{* * *}$ & $0.223^{* * *}$ \\
\hline & $(0.00442)$ & $(0.109)$ & $(0.0110)$ \\
\hline \multirow{4}{*}{ 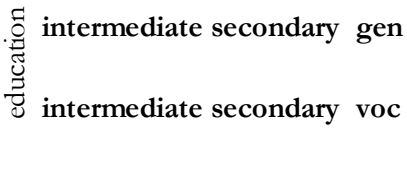 } & $0.0173^{* *}$ & $1.527 * * *$ & $0.244 * * *$ \\
\hline & $(0.00515)$ & $(0.142)$ & $(0.0145)$ \\
\hline & $0.0108^{* *}$ & $1.079 * * *$ & $0.153^{* * *}$ \\
\hline & $(0.00400)$ & $(0.118)$ & $(0.0105)$ \\
\hline \multirow[t]{2}{*}{ upper secondary gen } & -0.00501 & $0.370^{* * *}$ & $0.0962^{* * *}$ \\
\hline & $(0.00586)$ & $(0.0957)$ & $(0.0125)$ \\
\hline \multirow[t]{2}{*}{ upper secondary voc } & 0.00815 & $0.668^{* * *}$ & $0.0840^{* * *}$ \\
\hline & $(0.00418)$ & $(0.0898)$ & $(0.00784)$ \\
\hline tertiary & 0 & 0 & 0 \\
\hline \multicolumn{2}{|c|}{ F (all education levels) $30.73^{* * *}$} & $62.07 * * *$ & $137.14^{* * *}$ \\
\hline \multicolumn{2}{|c|}{ adj. $\mathbf{R}^{2} 0.010$} & 0.108 & 0.075 \\
\hline \multicolumn{2}{|c|}{ \# clusters 86} & 86 & 86 \\
\hline \multicolumn{2}{|c|}{ N 292,352} & 264,634 & 288,898 \\
\hline
\end{tabular}

Note: all columns refer to equation 2; gender, age, (age/10)2, marital status, West-Germany and working hours/week as covariates are included in all models; "tertiary" is reference for education dummies; clustered standard errors (occupation KldB 2-digit) in parantheses; ${ }_{\mathrm{p}} \mathrm{p}<0.05 *{ }^{*} \mathrm{p}<0.01{ }^{* * *} \mathrm{p}<0.001 ;$ Source $:$ Microcensus 2009 
Table 3: OLS-results of educational levels on occupational demands

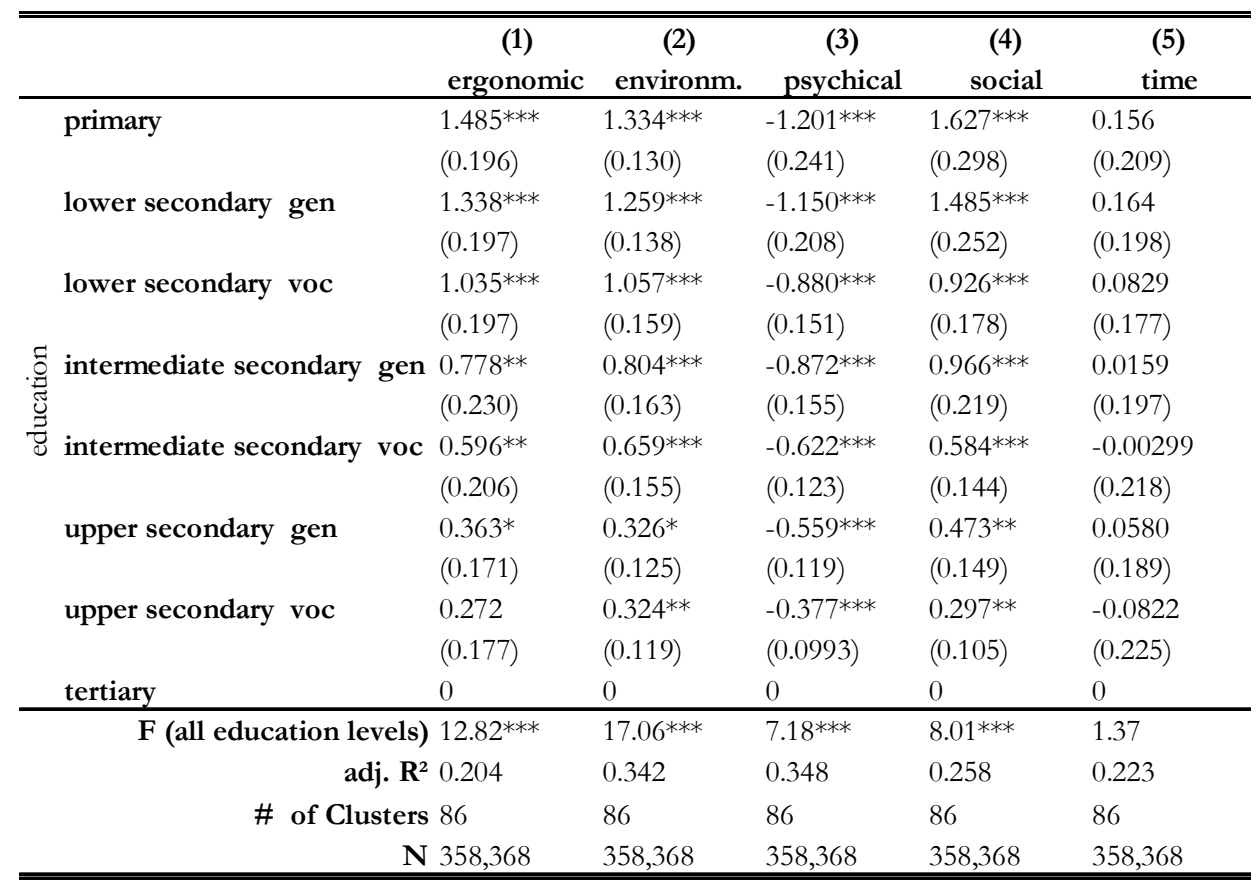

Note: all columns refer to equation 3; gender, age, (age/10) ${ }^{2}$, marital status, West-Germany and working hours/week are induded as covariatesin all models; " tertiary" is reference for education dummies; dustered standard errors

(occupation KldB 2-digit) in parantheses, ${ }^{*} \mathrm{p}<0.05 * * \mathrm{p}<0.01 * * * \mathrm{p}<0.001$; Source: Microcensus 2009 and Employment Survey 2006 
Table 4: OLS-results of occupational demands on bad health

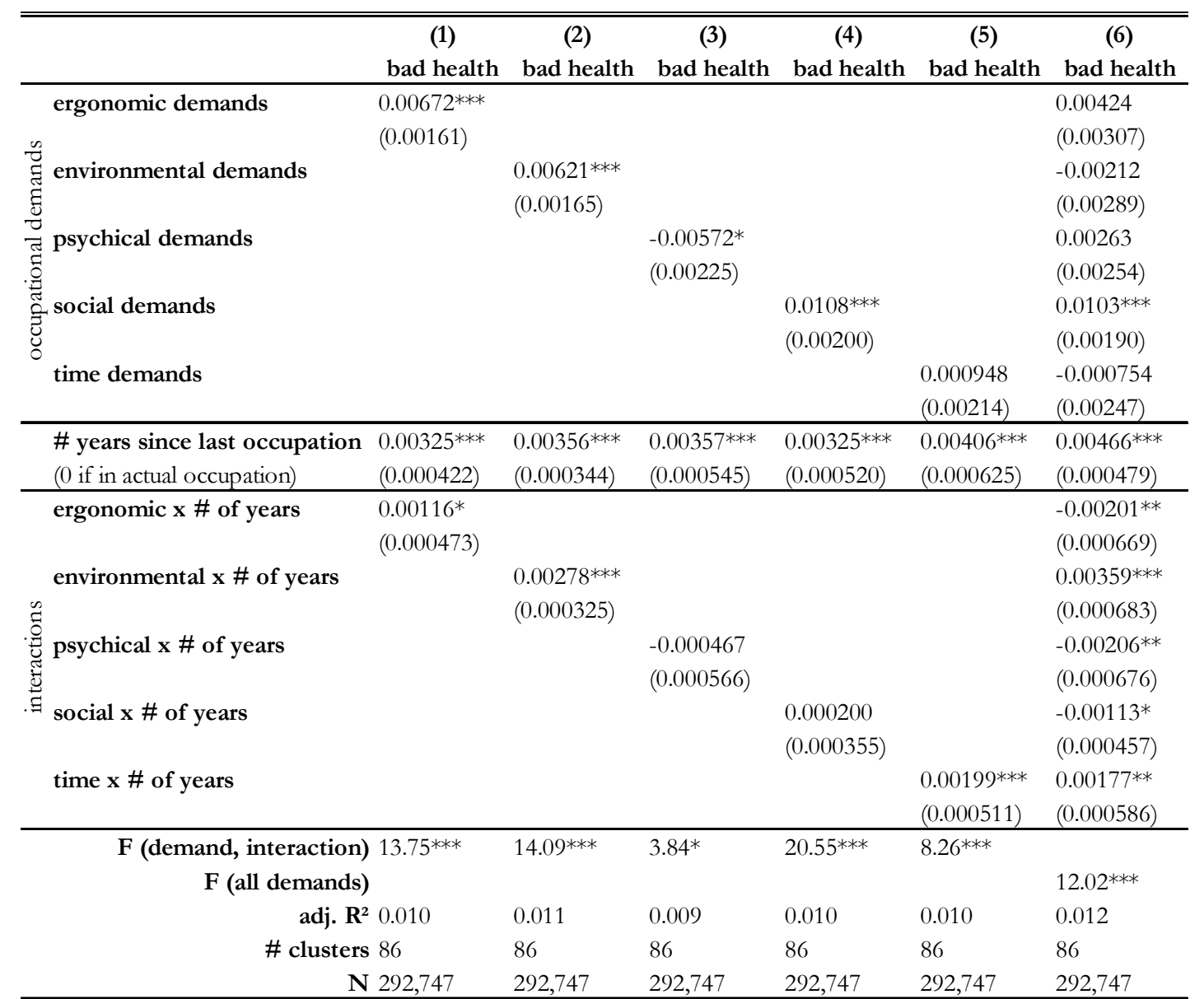

Note: all columns refer to equation 4; gender, age, (age/10) ${ }^{2}$, marital status, West-Germany and working hours/w eek as covariates are included in all models; "tertiary" is reference for education dummies; clustered standard errors (occupation KldB 2-digit) in parantheses; ${ }^{*} \mathrm{p}<0.05$ ${ }^{* *} \mathrm{p}<0.01{ }^{* * *} \mathrm{p}<0.001 ;$ Source : Microcensus 2009 and Employment Survey 2006 
Table 5: OLS-results of occupational demands on BMI

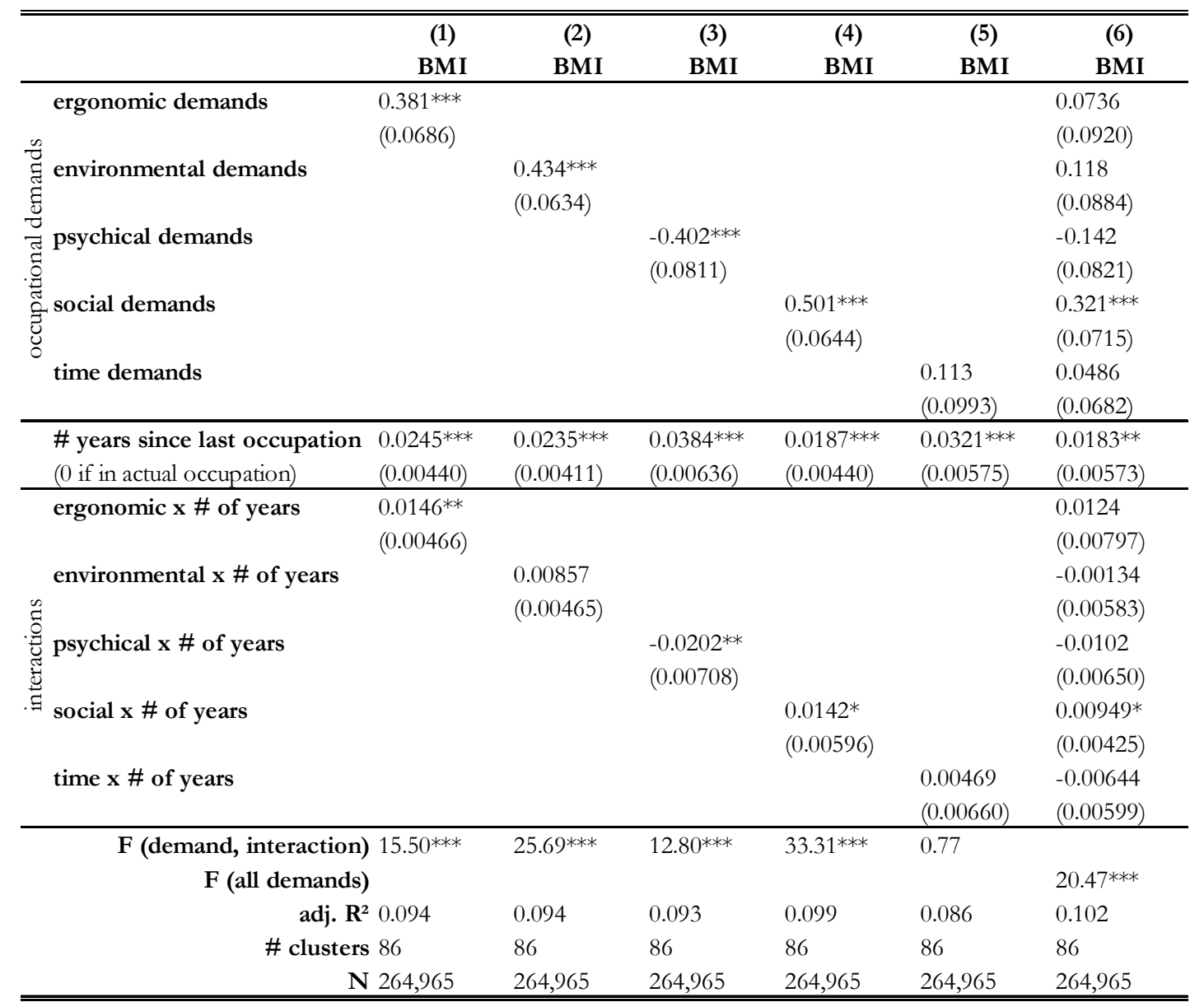

Note : all columns refer to equation 4; gender, age, (age/10) ${ }^{2}$, marital status, West-Germany and working hours/w eek as covariates are included in all models; "tertiary" is reference for education dummies; clustered standard errors (occupation KldB 2-digit) in parantheses; ${ }^{*} \mathrm{p}<0.05$ ${ }^{* *} \mathrm{p}<0.01{ }^{* * *} \mathrm{p}<0.001 ;$ Source : Microcensus 2009 and Employment Survey 2006 
Table 6: OLS-results of occupational demands on smoking status

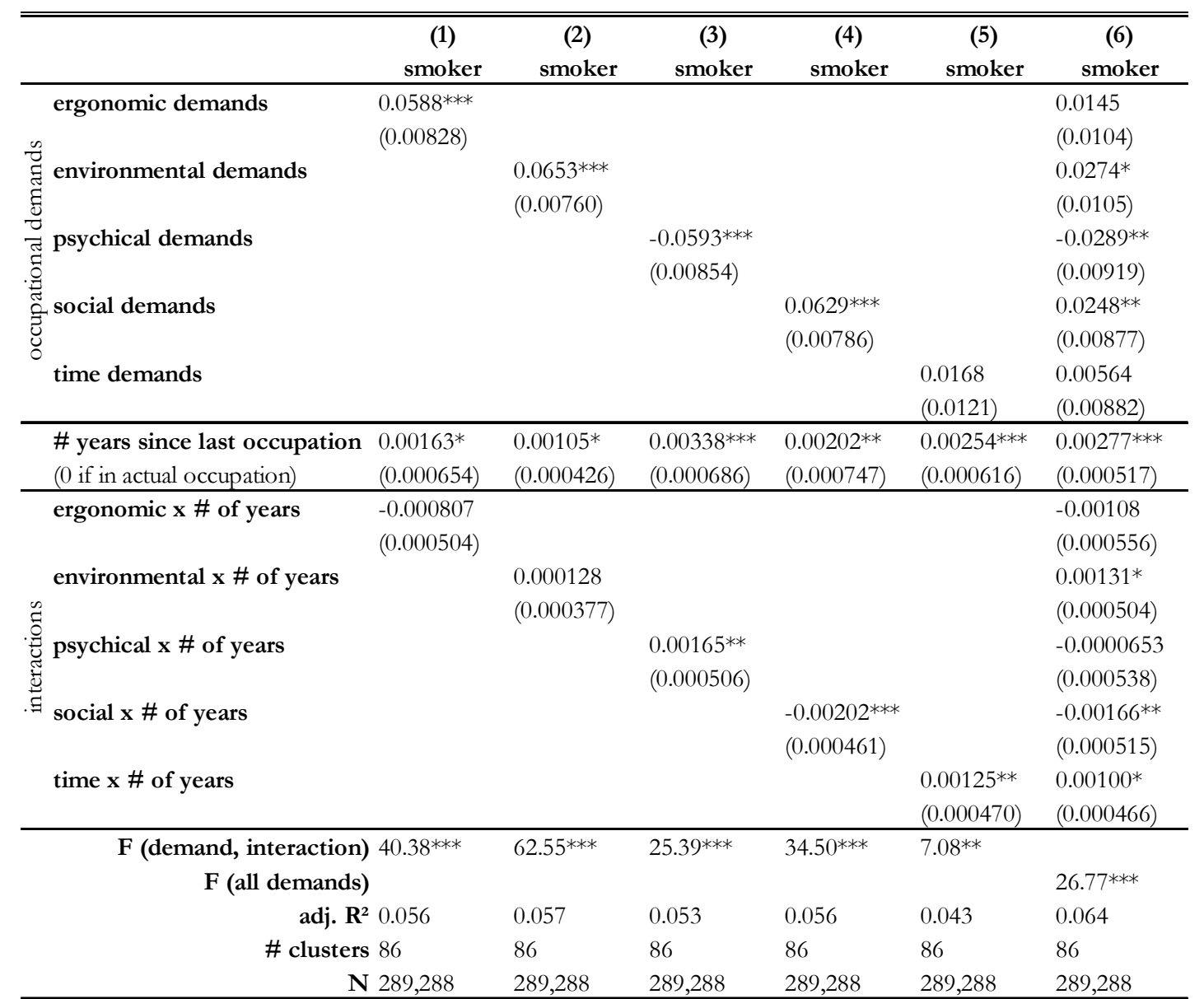

Note: all columns refer to equation 4; gender, age, (age/10) ${ }^{2}$, marital status, West-Germany and working hours/w eek as covariates are included in all models; "tertiary" is reference for education dummies; clustered standard errors (occupation KldB 2-digit) in parantheses; ${ }^{*} \mathrm{p}<0.05$ ${ }^{* *} \mathrm{p}<0.01{ }^{* * *} \mathrm{p}<0.001 ;$ Source : Microcensus 2009 and Employment Survey 2006 
Table 7: OLS-Results of mediating role of occupational demands on bad health

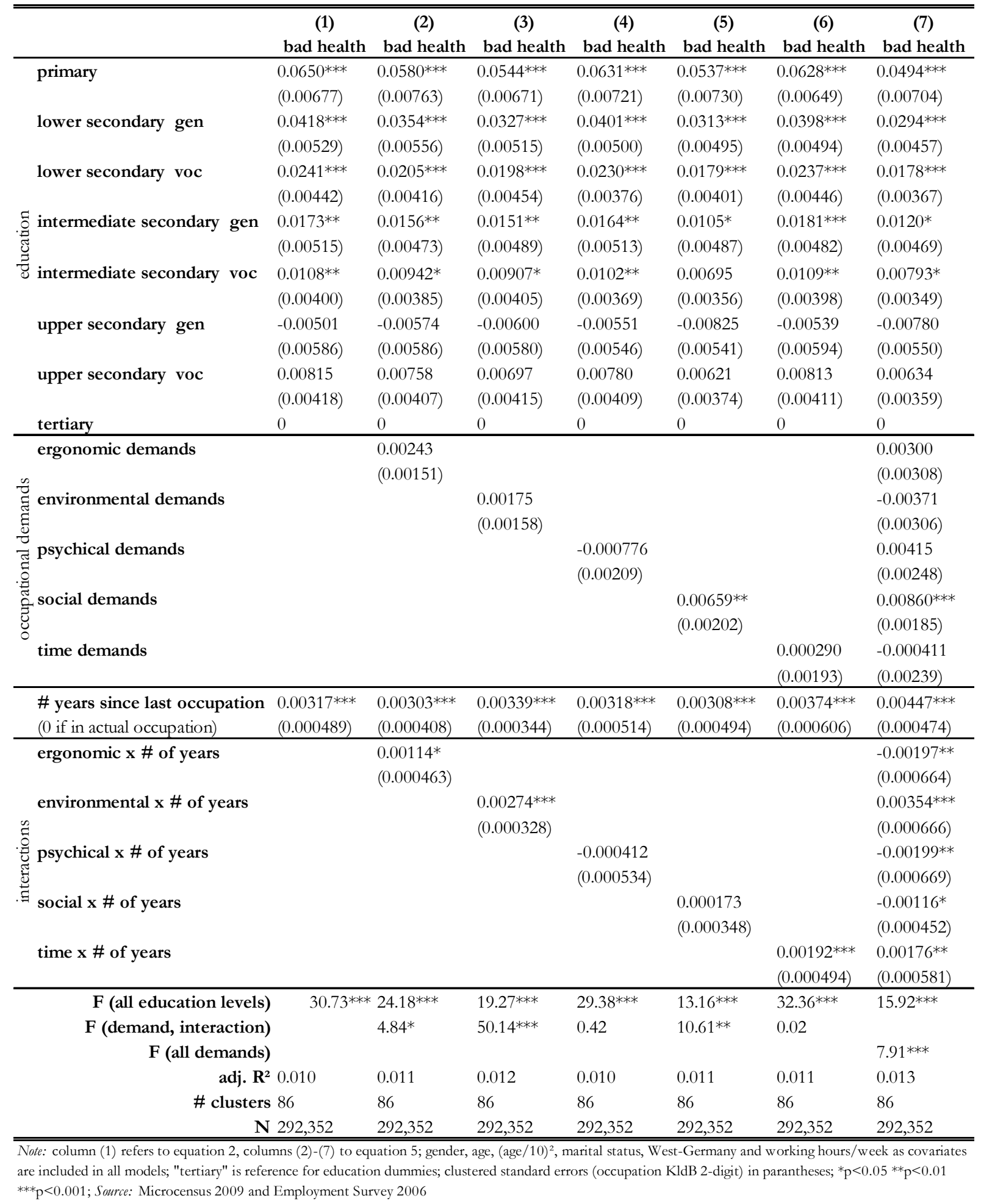


Table 8: OLS-Results of mediating role of occupational demands on BMI

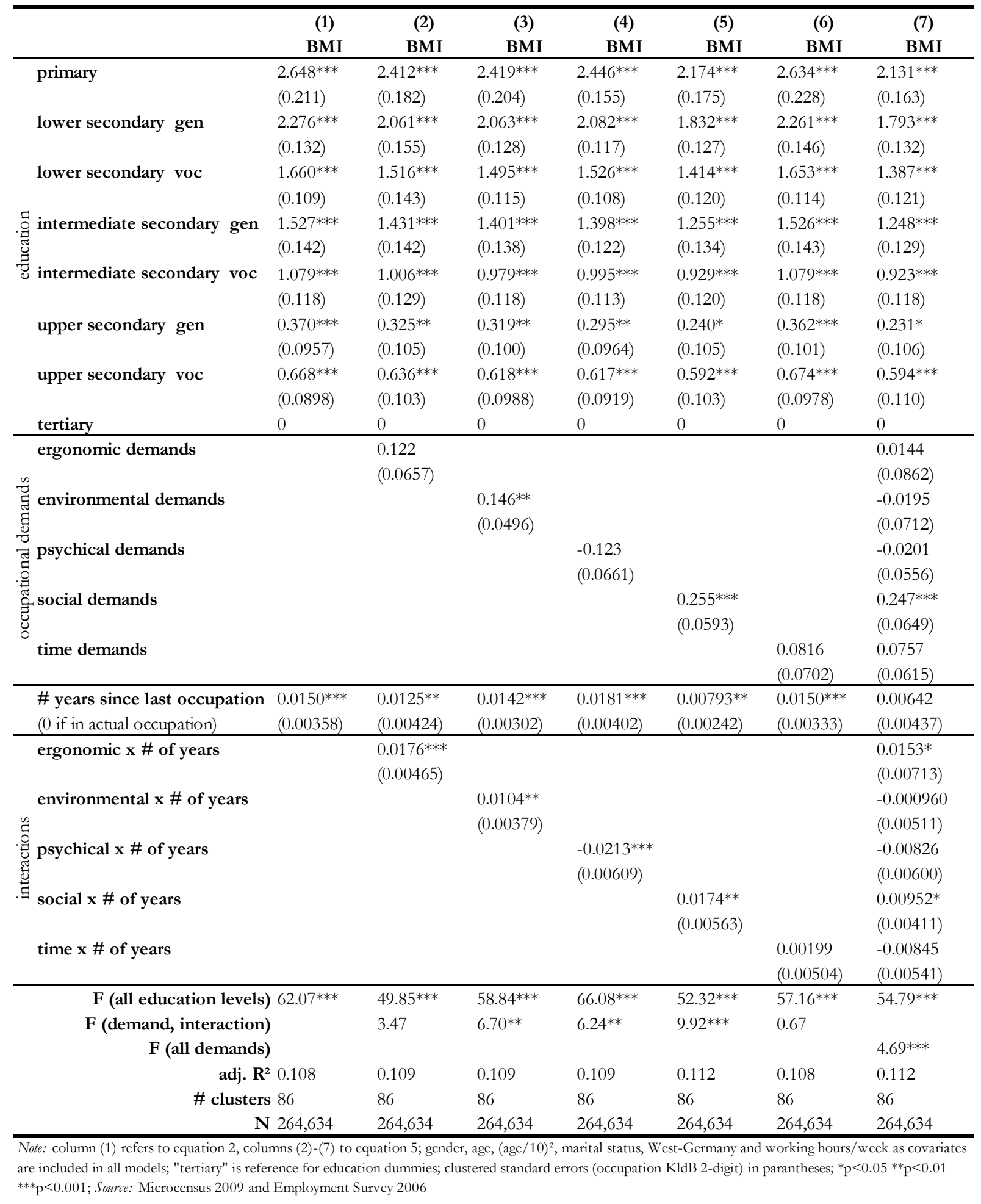


Table 9: OLS-Results of mediating role of occupational demands on smoking status

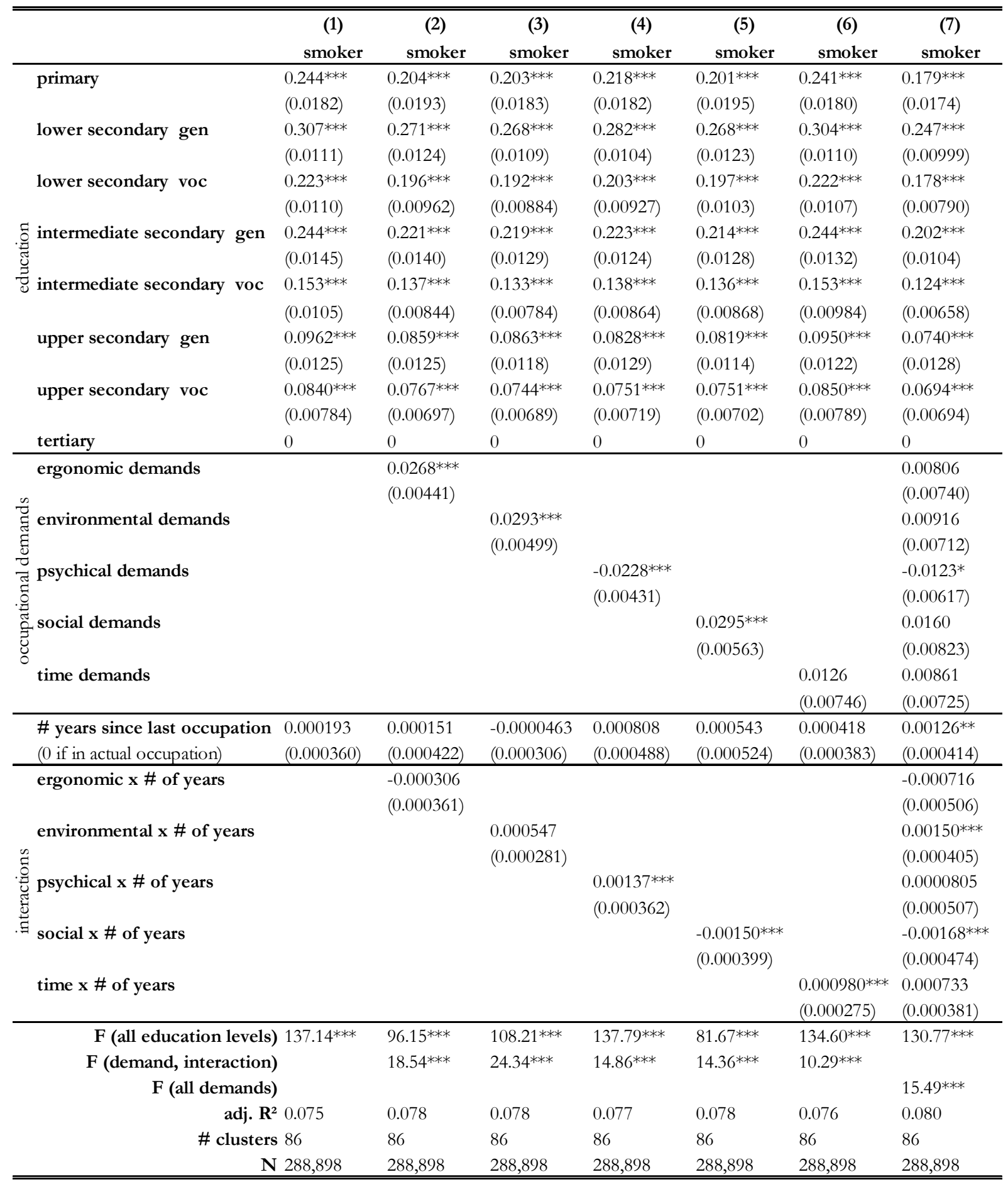

Note: column (1) refers to equation 2, columns (2)-(7) to equation 5; gender, age, (age/10) ${ }^{2}$, marital status, West-Germany and working hours/week as covariates are included in all models; "tertiary" is reference for education dummies; clustered standard errors (occupation KldB 2-digit) in parantheses; ${ }^{*} \mathrm{p}<0.05{ }^{* *} \mathrm{p}<0.01$ *** $\mathrm{p}<0.001$; Source: Microcensus 2009 and Employment Survey 2006 


\section{Appendix}

Table A1: summary statistics of analyzed samples

\begin{tabular}{|c|c|c|}
\hline & $\begin{array}{c}\text { Employment } \\
\text { Survey } 2006\end{array}$ & $\begin{array}{c}\text { Microcensus } \\
2009\end{array}$ \\
\hline Variables & mean $(\mathrm{sd})$ & mean (sd) \\
\hline female $[0 ; 1]$ & 0.4844 & 0.4983 \\
\hline age & $42.1336(9.44)$ & $45.4929(10.91)$ \\
\hline \# working hours & $39.3714(13.17)$ & $36.6014^{\mathrm{b}}(10.06)$ \\
\hline married $[0 ; 1]$ & 0.5471 & 0.6326 \\
\hline West-Germany $[0 ; 1]$ & 0.8106 & 0.7915 \\
\hline education primary & 0.0054 & 0.0237 \\
\hline (casmin) lower secondary gen & 0.0266 & 0.0696 \\
\hline lower secondary voc & 0.2016 & 0.2584 \\
\hline intermediate secondary gen & 0.0170 & 0.0238 \\
\hline intermediate secondary voc & 0.3164 & 0.3235 \\
\hline upper secondary gen & 0.0189 & 0.0211 \\
\hline upper secondary voc & 0.1197 & 0.0988 \\
\hline tertiary & 0.2944 & 0.1812 \\
\hline main occupation forestry, agriculture & 0.0175 & 0.0249 \\
\hline (KldB 1992) mining & 0.0008 & 0.0016 \\
\hline manufacturing & 0.1854 & 0.2107 \\
\hline engineering & 0.0818 & 0.0634 \\
\hline services & 0.7110 & 0.6884 \\
\hline others & 0.0035 & 0.0109 \\
\hline bad health $[0 ; 1]$ & $0.0952^{\mathrm{a}}$ & 0.1274 \\
\hline BMI & n.a. & $25.6636(4.45)$ \\
\hline smoker $[0 ; 1]$ & n.a. & 0.3165 \\
\hline $\mathbf{N}$ & 18,797 & 359,587 \\
\hline
\end{tabular}

Note: a: bad health is surveyed via self-rated health in the Employment Survey 2006; b: No. of working hours for currently employed people; Source: Employment Survey 2006 and Microcensus 2009 
Table A2: summary statistics of occupational demand items

\begin{tabular}{|c|c|c|c|}
\hline & $\begin{array}{l}\text { classification } \\
\text { cf. Kroll } 2011 \\
\end{array}$ & Items & Mean (SD) \\
\hline \multirow{13}{*}{ 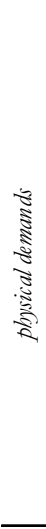 } & \multirow{13}{*}{$\begin{array}{l}\text { ergonomic } \\
\text { demands } \\
\text { environmental } \\
\text { demands }\end{array}$} & working in a standing position & $0.5097(0.4999)$ \\
\hline & & working while sitting & $0.1115(0.3147)$ \\
\hline & & lift and carry heavy charges & $0.1979(0.3984)$ \\
\hline & & working in forced positions & $0.1214(0.3266)$ \\
\hline & & working in dust, gas, fumes & $0.1172(0.3216)$ \\
\hline & & working in cold, heat, wet conditions & $0.1808(0.3848)$ \\
\hline & & working in dirt, oil, grease & $0.1442(0.3514)$ \\
\hline & & working with vibrations & $0.0382(0.1917)$ \\
\hline & & working with glaring/faint light & $0.0871(0.282)$ \\
\hline & & working with dangerous substances & $0.0649(0.2464)$ \\
\hline & & wearing protectiondothes while work & $0.1814(0.3853)$ \\
\hline & & working with noise & $0.2103(0.4076)$ \\
\hline & & working while others smoke & $0.1532(0.3602)$ \\
\hline \multirow{25}{*}{ 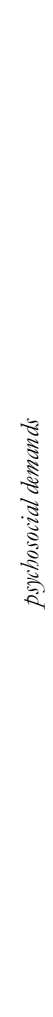 } & \multirow{10}{*}{$\begin{array}{l}\text { psychical } \\
\text { demands }\end{array}$} & deadline pressure/pressure to perform & $0.5656(0.4957)$ \\
\hline & & getting new tasks and become acquainted with it & $0.4279(0.4948)$ \\
\hline & & trying new or improving procedures & $0.3056(0.4607)$ \\
\hline & & being interrupted, disturbed while working & $0.4976(0.5001)$ \\
\hline & & minimum output or time is prescribed & $0.3031(0.4596)$ \\
\hline & & doing unlearned tasks & $0.0931(0.2905)$ \\
\hline & & doing or observing different tasks simultaneously & $0.6302(0.4828)$ \\
\hline & & minor mistakes have major financal consequences & $0.1571(0.3639)$ \\
\hline & & going to the limits of own performance/abilities & $0.1718(0.3772)$ \\
\hline & & working very fast & $0.4389(0.4962)$ \\
\hline & \multirow{10}{*}{$\begin{array}{l}\text { social } \\
\text { demands }\end{array}$} & feeling as a part of community & $0.0305(0.172)$ \\
\hline & & good cooperation with colleagues & $0.0059(0.0767)$ \\
\hline & & being supported by colleagues & $0.0177(0.1319)$ \\
\hline & & being supported by direct superior & $0.0546(0.2272)$ \\
\hline & & arranging work on own schedule & $0.0591(0.2358)$ \\
\hline & & having influence on amount of work & $0.2380(0.4259)$ \\
\hline & & taking breaks autonomously & $0.1832(0.3868)$ \\
\hline & & feeling that own work is important & $0.1461(0.1200)$ \\
\hline & & not being on notice of changes, decisions & $0.1426(0.35)$ \\
\hline & & receiving few information about own work & $0.0866(0.2813)$ \\
\hline & \multirow{5}{*}{$\begin{array}{l}\text { time } \\
\text { demands }\end{array}$} & working in shifts & $0.2261(0.4183)$ \\
\hline & & working on call & $0.1999(0.3999)$ \\
\hline & & working sometimes on saturdays & $0.6824(0.4655)$ \\
\hline & & working sometimes on sundays and holidays & $0.4426(0.4967)$ \\
\hline & & working sometimes between $11 \mathrm{pm}$ an $5 \mathrm{am}$ & $0.2301(0.4209)$ \\
\hline
\end{tabular}

Source: Employment Survey 2006 
Figure A1: occupational demands by educational level

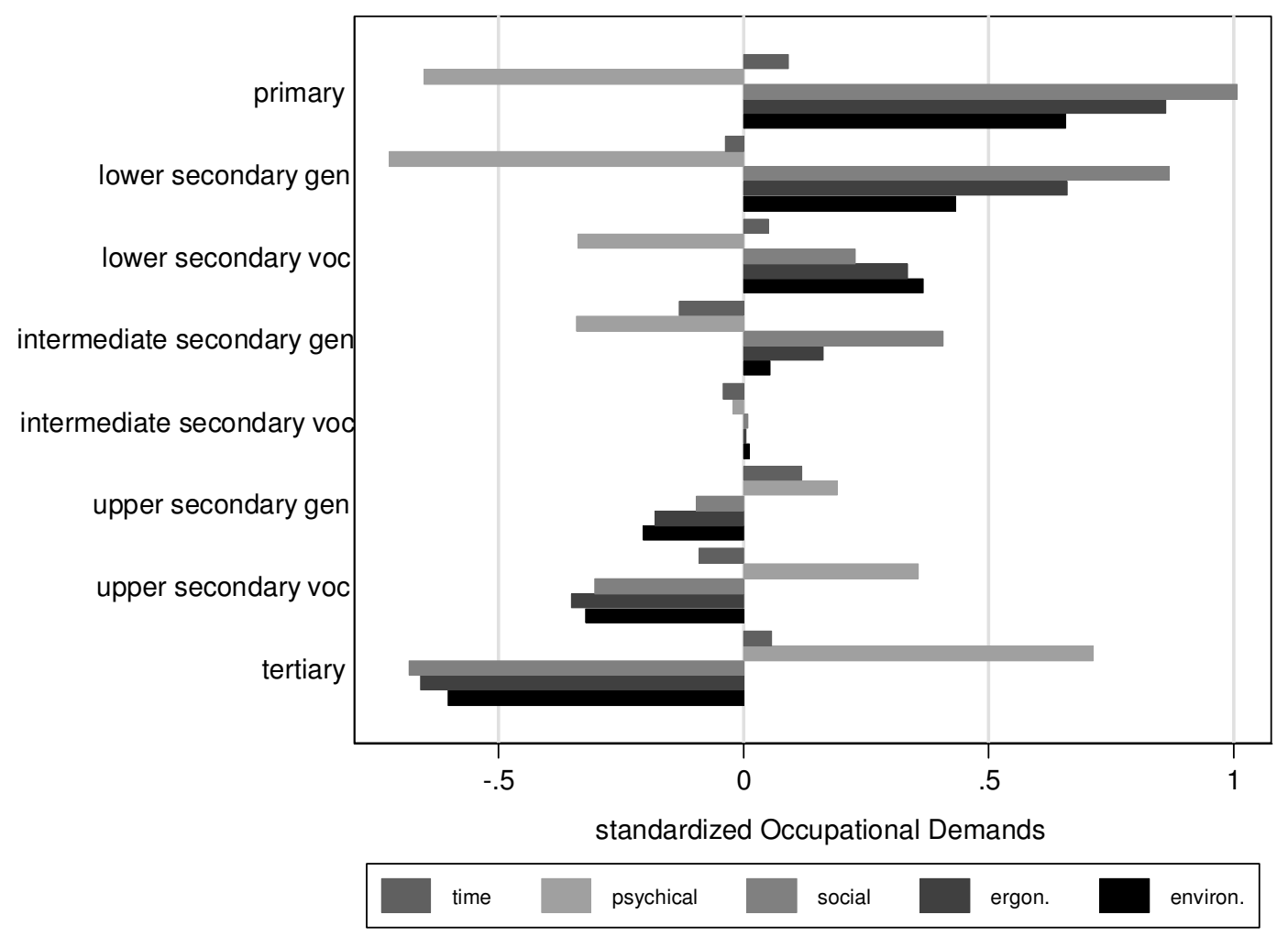

Source: Microcensus 2009 and Employment Survey 2006 
Figure A2: bad health and occupational demands
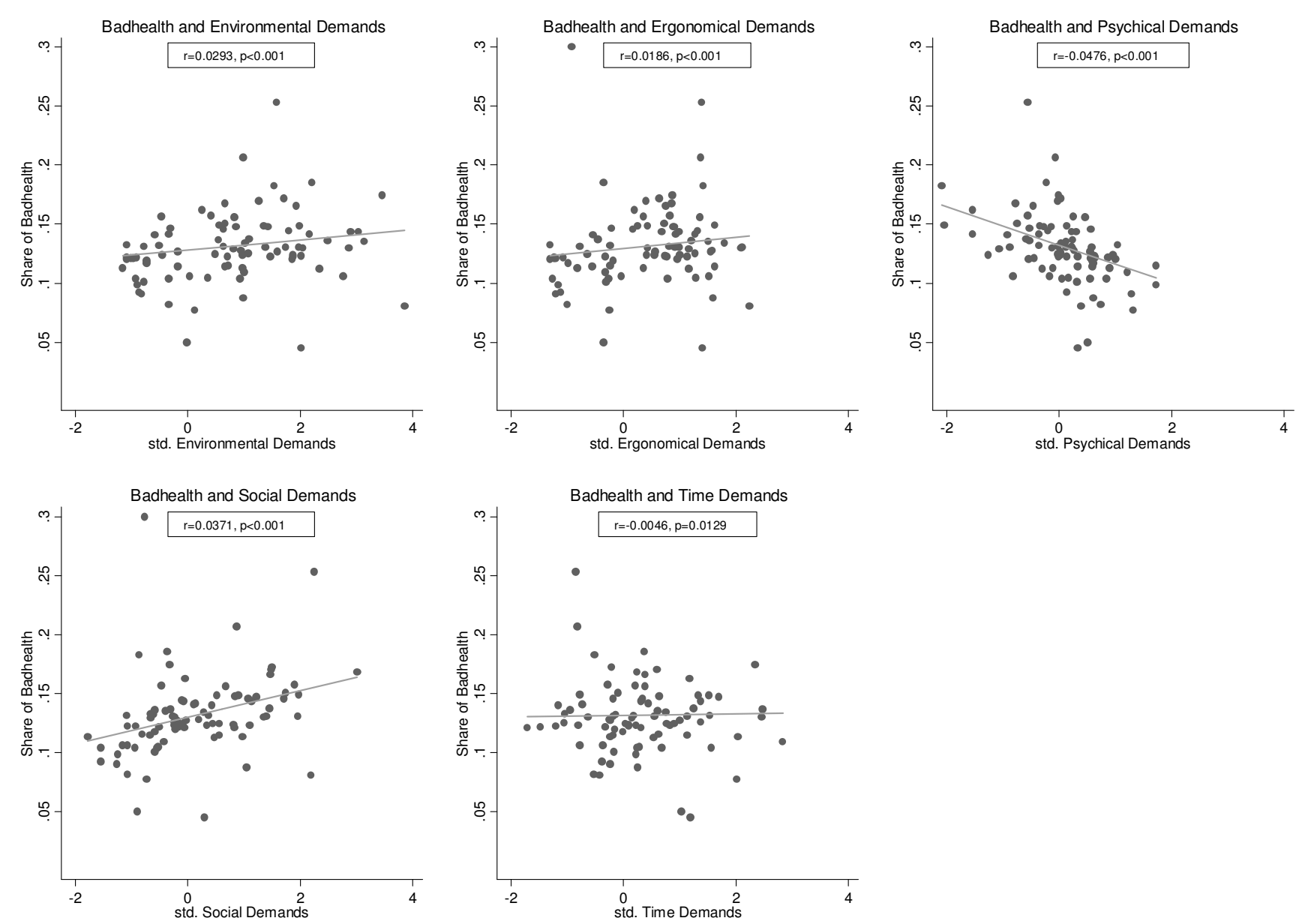

Note: average share of reporting bad health by occupational demands over occupational group; Source: Microcensus 2009 and Employment Survey 2006 
Figure A3: BMI and occupational demands
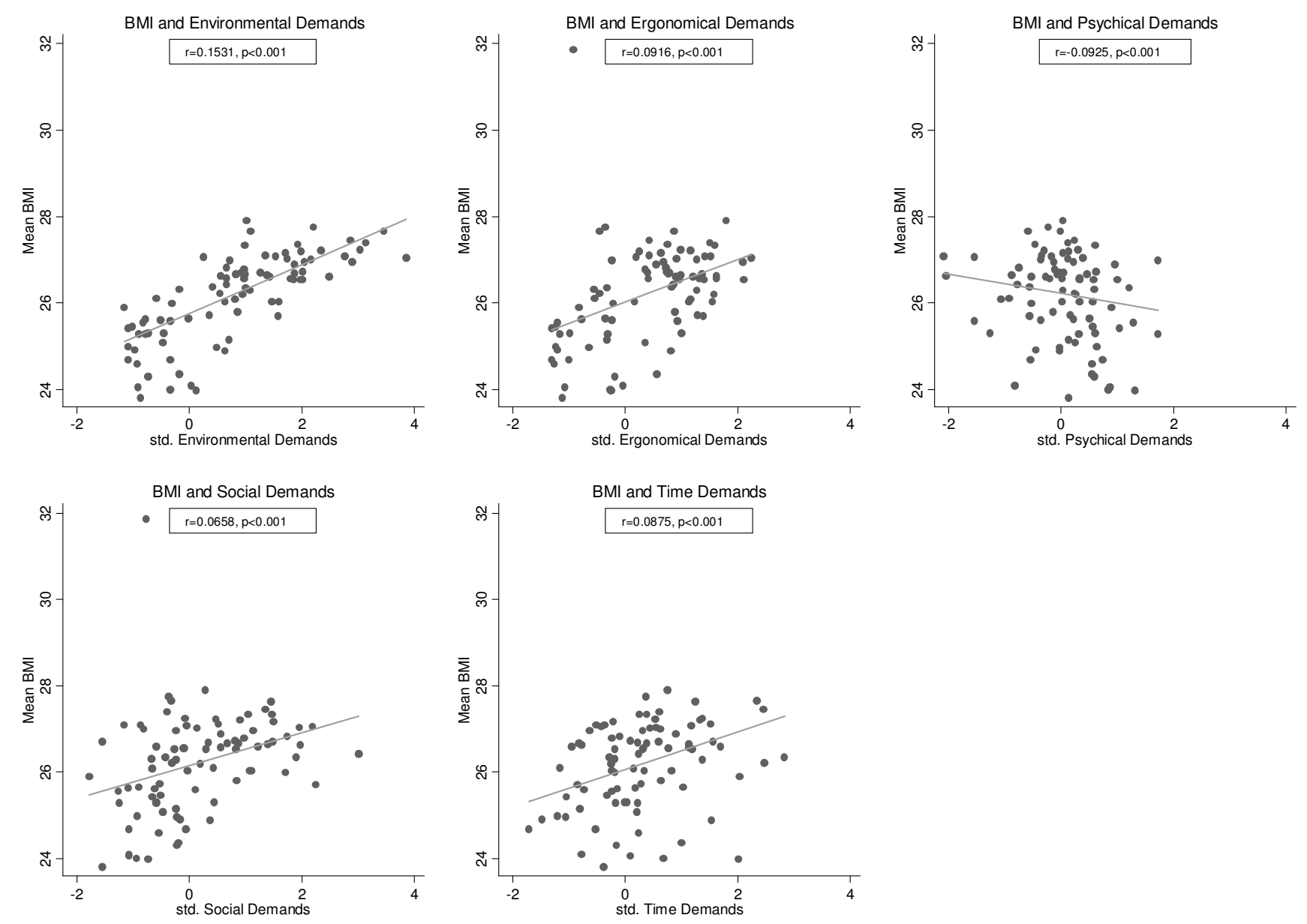

Note: average BMI by occupational demands over occupational group; Source: Microcensus 2009 and Employment Survey 2006 
Figure A4: smoking status and occupational demands
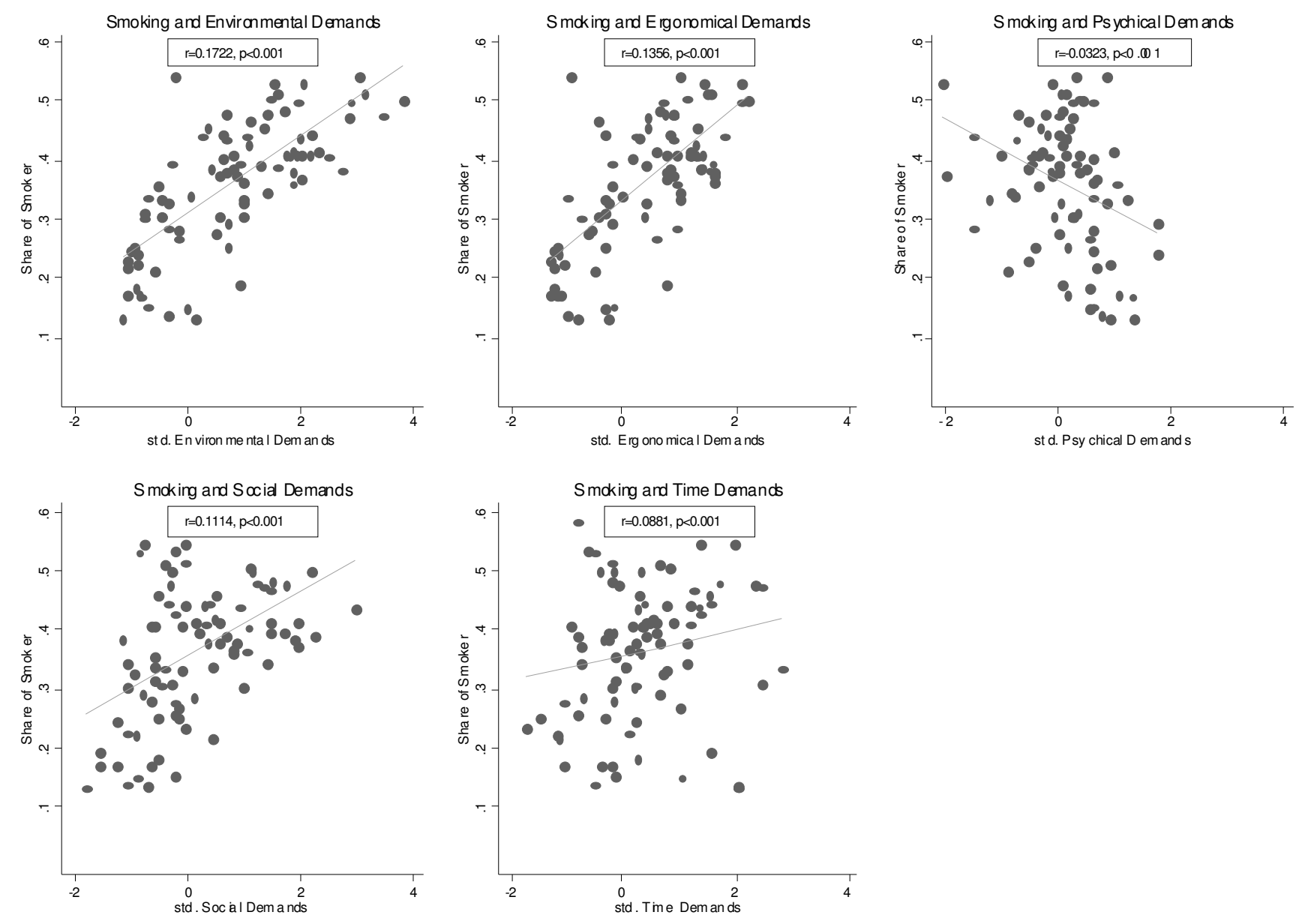

Note: average share of smokers by occupational demands over occupational group; Source: Microcensus 2009 and Employment Survey 2006 
Table A3: Change in education estimates on bad health after including demands (cf. Table 7; Figure A5)

\begin{tabular}{lrrrrrr}
\hline \hline \multirow{2}{*}{$\begin{array}{c}\text { bad health } \\
\text { education/demands }\end{array}$} & \multicolumn{2}{c}{$\%$ change in education coefficients } & & \\
ergonomic & environm. & psychical & social & time & all demands \\
\hline primary & -10.77 & -16.31 & -2.92 & -17.38 & -3.38 & $-24.00^{*}$ \\
& $(0.92)$ & $(1.58)$ & $(0.26)$ & $(1.55)$ & $(0.34)$ & $(2.22)$ \\
lower secondary gen & -15.31 & -21.77 & -4.07 & $-25.12^{*}$ & -4.78 & $29.67^{*}$ \\
& $(1.15)$ & $(1.77)$ & $(0.34)$ & $(2.12)$ & $(0.40)$ & $(2.71)$ \\
lower secondary voc & -14.94 & -17.84 & -4.56 & -25.73 & -1.66 & -26.14 \\
& $(0.87)$ & $(0.95)$ & $(0.29)$ & $(1.55)$ & $(0.09)$ & $(1.72)$ \\
intermediate sec. gen & -9.83 & -12.72 & -5.20 & -39.31 & 4.62 & -30.64 \\
& $(0.36)$ & $(0.45)$ & $(0.18)$ & $(1.40)$ & $(-0.17)$ & $(1.13)$ \\
intermediate sec. voc & -12.78 & -16.02 & -5.56 & -35.65 & 0.93 & -26.57 \\
& $(0.36)$ & $(0.43)$ & $(0.16)$ & $(1.08)$ & $(-0.03)$ & $(0.82)$ \\
upper secondary gen & 14.57 & 19.76 & 9.98 & 64.67 & 7.58 & 55.69 \\
& $(0.12)$ & $(0.17)$ & $(0.09)$ & $(0.60)$ & $(0.06)$ & $(0.51)$ \\
upper secondary voc & -6.99 & -14.48 & -4.29 & -23.80 & -0.25 & -22.21 \\
& $(0.14)$ & $(0.28)$ & $(0.09)$ & $(0.52)$ & $(0.01)$ & $(0.50)$ \\
tertiary & ref. & ref. & ref. & ref. & ref. & ref. \\
\hline \hline
\end{tabular}

Note: t-values in parentheses, ${ }^{*} \mathrm{p}<0.05 ;$ Source: Microcensus 2009 and Employment Survey 2006

Table A4: Change in education estimates on BMI after including demands (cf. Table 8; Figure A6)

\begin{tabular}{|c|c|c|c|c|c|c|}
\hline \multirow{2}{*}{$\begin{array}{c}\text { BMI } \\
\text { education/demands }\end{array}$} & \multicolumn{6}{|c|}{ \% change in education coefficients } \\
\hline & ergonomic & environm. & psychical & social & time & all demands \\
\hline \multirow[t]{2}{*}{ primary } & -8.91 & -8.65 & -7.63 & $-17.90^{*}$ & -0.53 & $-19.52 *$ \\
\hline & $(1.30)$ & $(1.12)$ & $(1.30)$ & $(2.71)$ & $(0.06)$ & $(3.17)$ \\
\hline \multirow[t]{2}{*}{ lower secondary gen } & -9.45 & -9.36 & -8.52 & $-19.51 *$ & -0.66 & $-21.22 *$ \\
\hline & $(1.39)$ & $(1.66)$ & $(1.66)$ & $(3.50)$ & $(0.10)$ & $(3.66)$ \\
\hline \multirow[t]{2}{*}{ lower secondary voc } & -8.67 & -9.94 & -8.07 & $-14.82 *$ & -0.42 & $-16.45^{*}$ \\
\hline & $(1.01)$ & (1.43) & $(1.24)$ & $(2.05)$ & $(0.06)$ & $(2.26)$ \\
\hline \multirow[t]{2}{*}{ intermediate sec. gen } & -6.29 & -8.25 & -8.45 & $-17.81 *$ & -0.07 & $-18.27 *$ \\
\hline & $(0.68)$ & $(0.91)$ & $(1.06)$ & $(2.03)$ & $(0.01)$ & $(2.16)$ \\
\hline \multirow[t]{2}{*}{ intermediate sec. voc } & -6.77 & -9.27 & -7.78 & -13.90 & 0.00 & -14.46 \\
\hline & $(0.57)$ & $(0.85)$ & $(0.74)$ & $(1.25)$ & 0.00 & $(1.32)$ \\
\hline \multirow[t]{2}{*}{ upper secondary gen } & -12.16 & -13.78 & -20.27 & -35.14 & -2.16 & -37.57 \\
\hline & $(0.43)$ & 0.51 & $(0.78)$ & $(1.24)$ & $(0.08)$ & $(1.31)$ \\
\hline \multirow[t]{2}{*}{ upper secondary voc } & -4.79 & -7.49 & -7.63 & -11.38 & 0.90 & -11.08 \\
\hline & $(0.31)$ & $(0.51)$ & $(0.55)$ & $(0.74)$ & $(-0.06)$ & $(0.67)$ \\
\hline tertiary & ref. & ref. & ref. & ref. & ref. & ref. \\
\hline
\end{tabular}


Table A5: Change in education estimates on smoking after including demands (cf. Table 9; Figure A7)

\begin{tabular}{|c|c|c|c|c|c|c|}
\hline \multirow{2}{*}{$\begin{array}{l}\text { smoker } \\
\text { education/demands }\end{array}$} & \multicolumn{6}{|c|}{ \% change in education coefficients } \\
\hline & ergonomic & environm. & psychical & social & time & all demands \\
\hline \multirow[t]{2}{*}{ primary } & $-16.39 *$ & $-16.80^{*}$ & -10.66 & $-17.62^{*}$ & -1.23 & $-26.64^{*}$ \\
\hline & $(2.07)$ & $(2.24)$ & $(1.43)$ & $(2.21)$ & $(0.17)$ & $(3.74)$ \\
\hline \multirow[t]{2}{*}{ lower secondary gen } & $-11.73^{*}$ & $-12.70^{*}$ & $-8.143^{*}$ & $-12.70^{*}$ & -0.98 & $-19.54^{*}$ \\
\hline & $(2.90)$ & $(3.58)$ & $(2.40)$ & $(3.17)$ & $(0.27)$ & $(6.01)$ \\
\hline \multirow[t]{2}{*}{ lower secondary voc } & $-12.11 *$ & $-13.90^{*}$ & $-8.97 *$ & $-11.66^{*}$ & -0.45 & $-20.18^{*}$ \\
\hline & $(2.81)$ & $(3.51)$ & (2.16) & $(2.52)$ & $(0.09)$ & $(5.70)$ \\
\hline \multirow[t]{2}{*}{ intermediate sec. gen } & -9.43 & -10.25 & -8.61 & $-12.30^{*}$ & 0.00 & $-17.21 *$ \\
\hline & $(1.64)$ & $(1.94)$ & $(1.69)$ & $(2.34)$ & 0.00 & $(4.04)$ \\
\hline \multirow[t]{2}{*}{ intermediate sec. voc } & -10.46 & -13.07 & -9.80 & -11.11 & 0.00 & $-18.95^{*}$ \\
\hline & $(1.90)$ & $(2.55)$ & (1.74) & $(1.96)$ & 0.00 & (4.41) \\
\hline \multirow[t]{2}{*}{ upper secondary gen } & -10.71 & -10.29 & -13.93 & -14.86 & -1.25 & -23.08 \\
\hline & $(0.82)$ & $(0.84)$ & $(1.04)$ & $(1.25)$ & $(0.10)$ & $(1.73)$ \\
\hline \multirow[t]{2}{*}{ upper secondary voc } & -8.69 & -11.43 & -10.60 & -10.60 & 1.19 & $-17.38^{*}$ \\
\hline & $(1.05)$ & $(1.39)$ & $(1.24)$ & $(1.27)$ & $(-0.13)$ & (2.10) \\
\hline tertiary & ref. & ref. & ref. & ref. & ref. & ref. \\
\hline
\end{tabular}

Note: t-values in parentheses, ${ }^{*} \mathrm{p}<0.05$; Source: Microcensus 2009 and Employment Survey 2006 
Figure A5: change in education estimates on bad health after including occupational demands (cf. Table 7; Table A3)
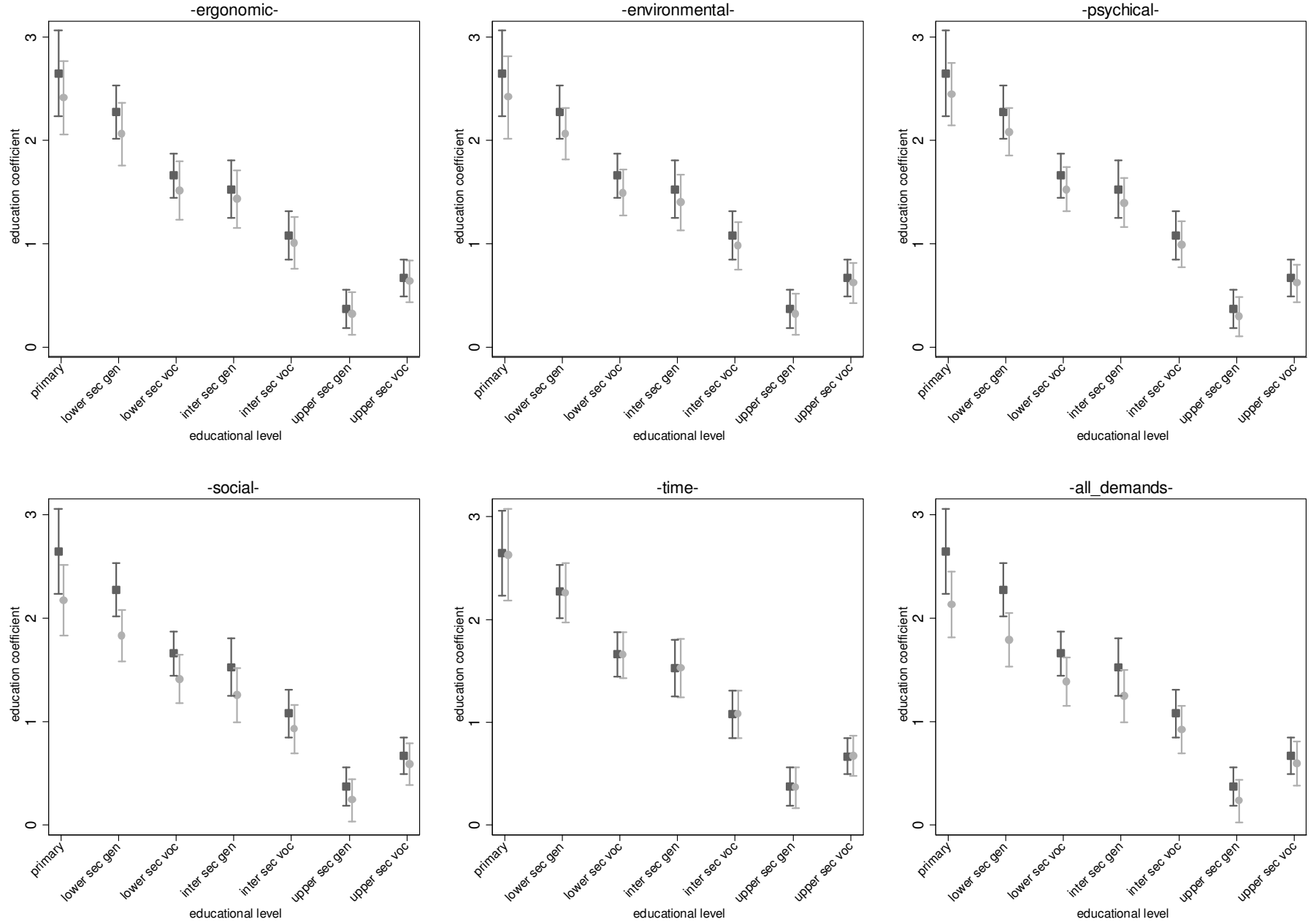

Note: black triangles belong to the raw education coefficients (Equation 2) and its $95 \%$-CI (black); grey circles belong to education coefficients adjusted for occupational demands (Equation 5 ) and its $95 \%$ CI (grey); "tertiary" is reference for education dummies; Source: Microcensus 2009 and Employment Survey 2006 
Figure A6: change in education estimates on BMI after including occupational demands (cf. Table 8; Table A4)
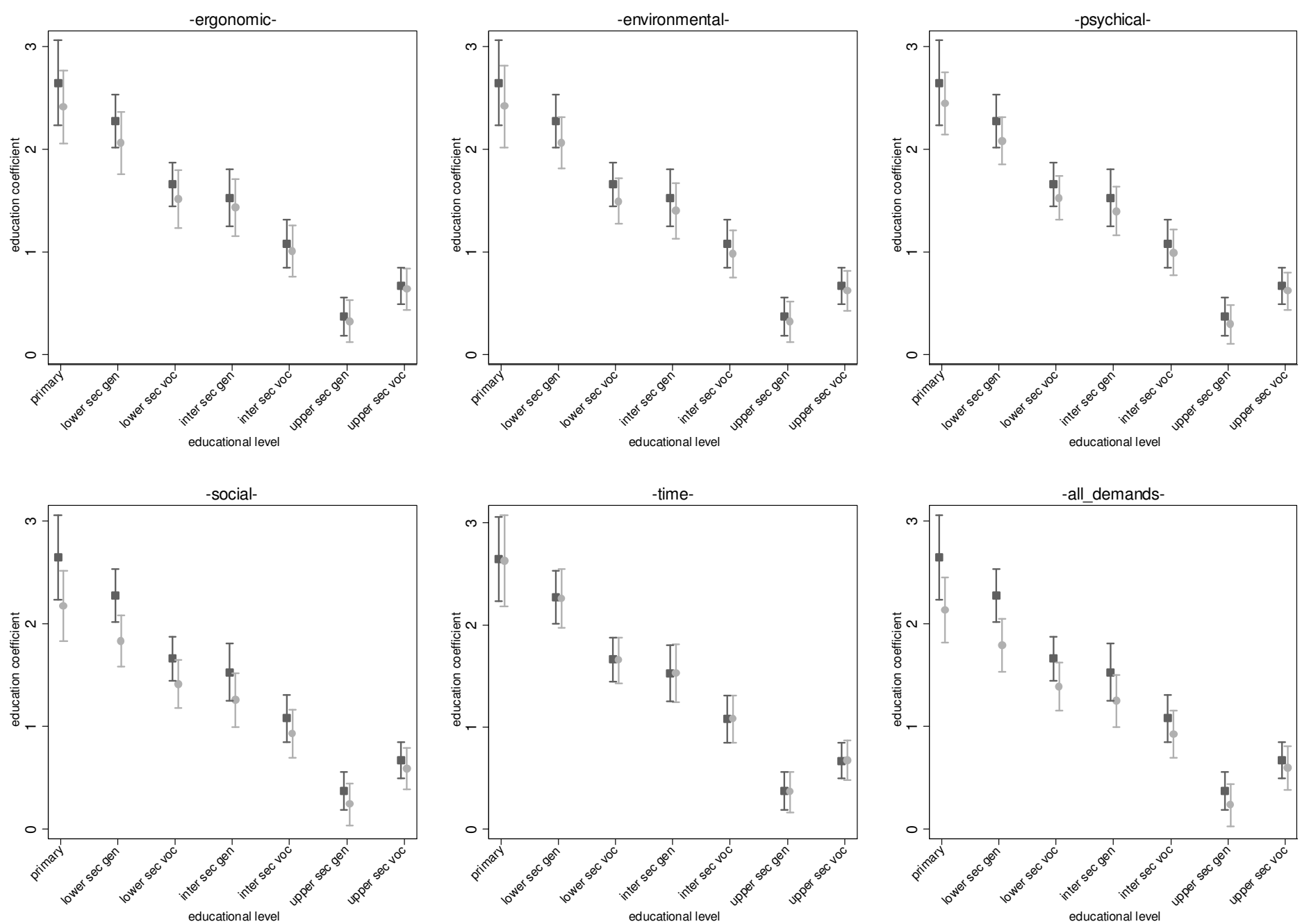

Note: black squares belong to the raw education coefficients (Equation 2) and its $95 \%$-CI; grey circles belong to education coefficients adjusted for occupational demands (Equation 5 ) and its $95 \%$-CI; "tertiary" is reference for education dummies; Source: Microcensus 2009 and Employment Survey 2006 
Figure A7: change in education estimates on smoking status after including occupational demands (cf. Table 9; Table A5)

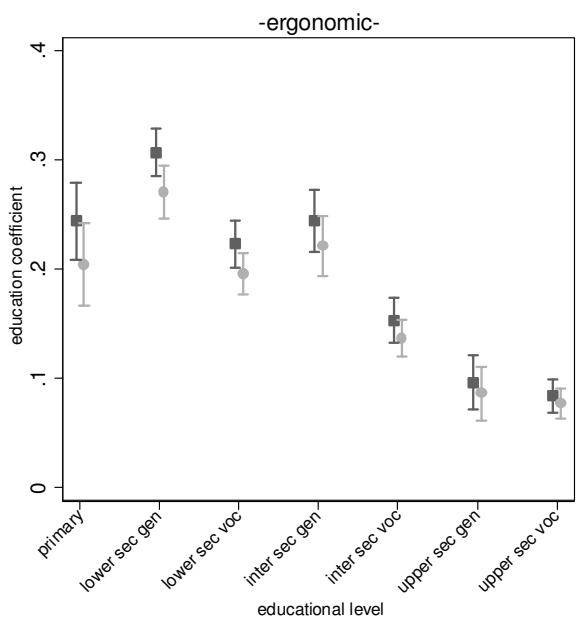

-environmental-

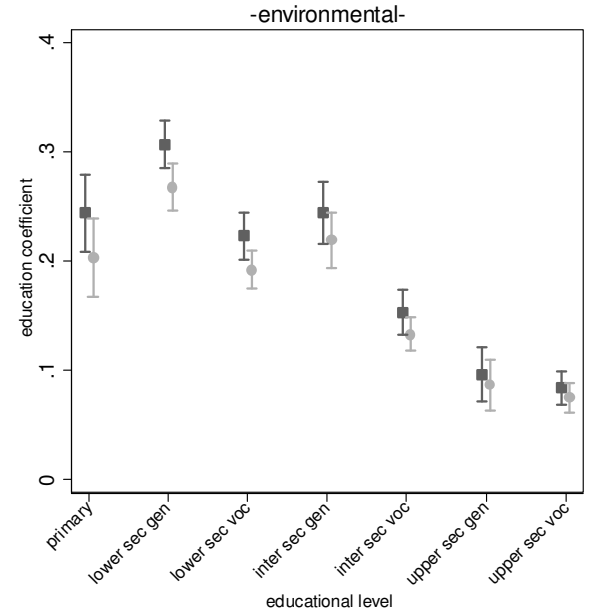

-time-
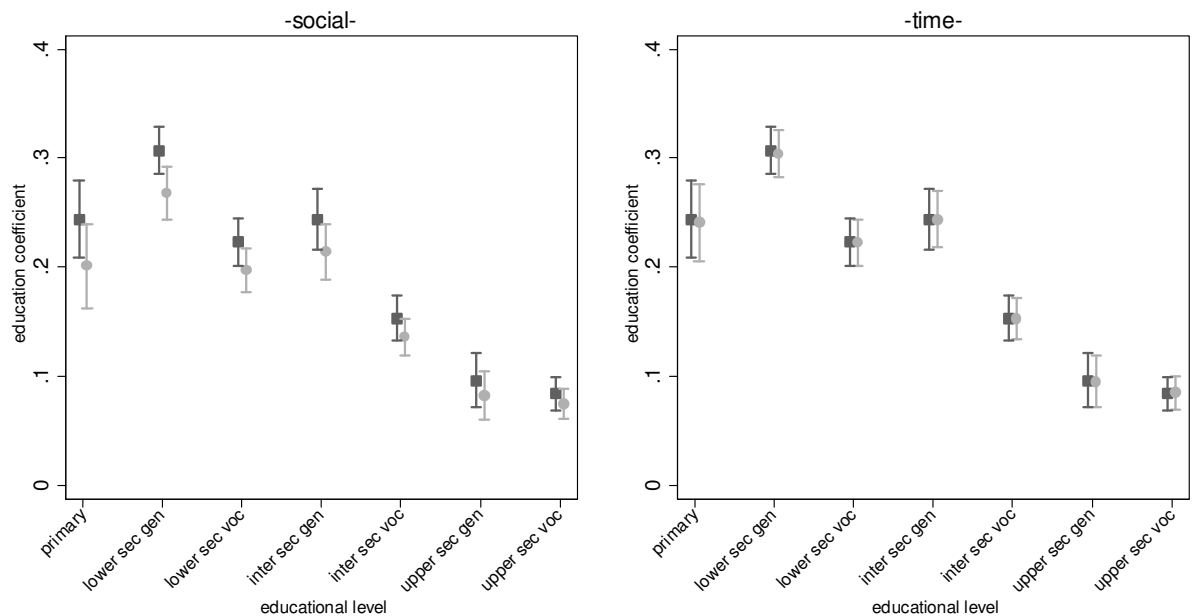

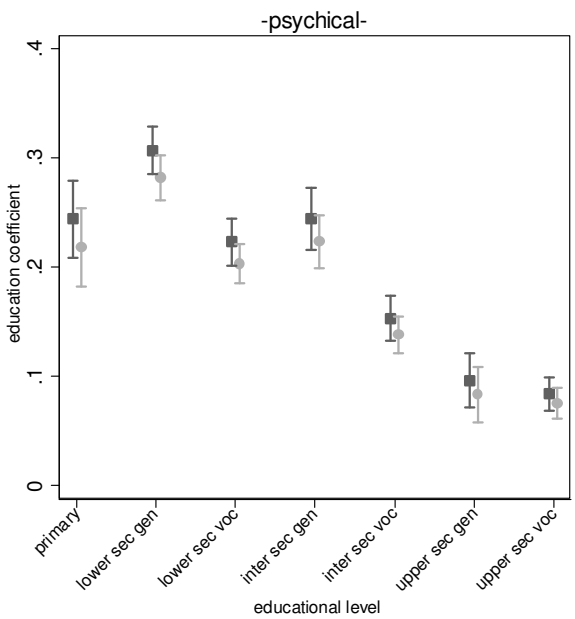

-all_demands-

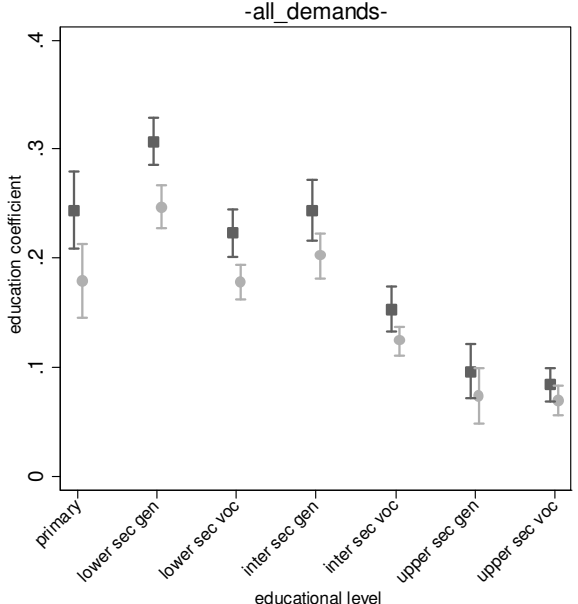

Note: black squares belong to the raw education coefficients (Equation 2) and its $95 \%$-CI; grey circles belong to education coefficients adjusted for occupational demands (Equation 5 ) and its $95 \%$-CI; "tertiary" is reference for education dummies; Source: Microcensus 2009 and Employment Survey 2006 
